\title{
MEDIANDO RELACIONES. REDES SOCIALES Y CAMBIO POLÍ́TICO A FINALES DEL ANTIGUO RÉGIMEN
}

por

\section{CHRISTIAN WINDLER}

Universidad de Basilea, Suiza/F.N.R.S.

RESUMEN: A través de un análisis microbistórico centrado en una agrociudad andaluq̧a (Priego de Córdoba), este articulo aporta elementos para una bistoria social de la mediación a finales del Antiguo Régimen. Enfoca, por un lado, lastestrategias de un intermediario especializado en el trato con la Real Chancilleria de Granada, y, por otro, su posicion dentro del municipio. Con ello, se exponen las interacciones entre las redes locales, el desarrollo de una cultura jurídica más profesionalizada y la creciente importancia de las instancias judiciales dependientes de la Corona en la sociedad española del siglo XVIII. El autor concluye que la reorganización de las relaciones burocráticas según un modelo clientelar iba configurando formas peculiares de estatalidad. Sin embargo, ésto no era la caracteristica de un mundo rural tradicional, sino, al contrario, parte de estrategias eficientes y racionales a su manera, que permitian participar de manera activa en la formación de un espacio político nacional.

Palabras ClaVe: Patronazgo. Mediación. Formación del Estado. España, siglos XVmL/XXX.

ABSTRACT: Througb a microbistorical approach focused on an Andalusian agrotown (Priego de Cordoba), this article contributes to a social bistory of brokerage at the end of the Old Regime. It throws light on the strategies of a broker who specialized in relations with the royal tribunal of Granada (Real Chancilleria), and on bis position within the local community. The article describes the interactions between local networks, the development of a more professionalized legal culture and the growing importance of royal jurisdiction within the Spanish society of the 18 th century. The author concludes that the reorganization of bureaucratic relations into patron-client ties shaped particular patterns of state-building. This was, bowever, not characteristic of a traditional rural world, but, on the contrary, part of efficient and rational strategies, that allowed active participation in the formation of a national political spbere.

KEY wORDS: Patronage. Brckerage. State-building. Spain, 18th and 19th century. 
Según los antropólogos que se han interesado por el Mediterráneo, el estudio de las redes de parentesco, amistad y patronazgo es imprescindible para entender las prácticas de observación y de comunicación, las formas de convivencia y, en particular, los procesos de toma de decisión política. Así, Ch. Giordano, en un estudio comparativo sobre las políticas de reforma y desarrollo que se aplicaron durante las pasadas décadas en el Mezzogiorno italiano y en el sur de España y Portugal, viene a pensar que éstas, a pesar de la transformación profunda del modo de vida y de los usos de consumo, habrían contribuido más bien «a la persistencia que a la transformación de los modelos de pensar y de actuar de las sociedades mediterráneas.» La economía del bienestar — distribución de subsidios estatales, rentas y puestos de trabajo en el sector público-- habría «resultado un ámbito ideal para la infiltración y difusión de transacciones practicadas desde bace siglos (...) sobre la base de relaciones clientelaress ' 1 . Aunque, según Ch. Giordano, estas relaciones clientelares, como tales, no representan ninguna peculiaridad de la Europa mediterránea, resultaría en cambio llamativo cómo aquí «los sistemas burocráticos no rara vez, se ban reorganizado en su totalidad según un modelo clientelar» ${ }^{2}$.

Analizando los efectos y las deficiencias de la articulación del Estado unitario en la península italiana, antropólogos, politólogos y sociólogos coinciden en señalar la importancia de tales procesos de sinfiltración, socavamiento y neutralización de instituciones estataless' ${ }^{3}$. En España, en especial medida entre los historiadores, el interés cientifico por estas problemáticas ha nacido más recientemente, aunque la perspectiva histórica aparezca clave para entender las modalidades de la superposición de poderes burocráticos que han acuñado una mentalidad para la que tales comportamientos son legítimos y racionales ${ }^{4}$. En vistas del papel importante del «enchufe», de los amigos, de los gestores profesionales $\mathrm{u}$ ocasionales, resulta sorprendente el hecho de que la investigación histótica en

1 GIORDANO, Christian, Die Betrogenen der Geschichte. Überlagerungsmentalität und Überlagerungsrationalität in mediterranen Gesellschaffen, Francfort del Meno/Nueva York, 1992, 241-282. Citas: 266-267. Esta obra contiene una amplia bibliografia sobre el Mezzogiomo y el sur de España y Portugal. Cf. DAvIS, John H., People of the Mediterranean An Essay in Comparative Social Anthropology, London, 1977, GELLNER, Ernest, WATERBURY, John, eds., Patrons and Clients in Mediterranean Societies, Londres, 1977; SCHNEIDER, Jane/SCHNEIDER, Peter, Culture and Political Economy in Western Sicity, Nueva York, 1976. El autor agradece al profesor Bernard Vincent (EHESS, Paris) por la lectura crítica de una primera versión del artículo.

2 GIORDANO, op. cit., 1992, 387-399, cita: 392.

3 GIORDANO, op. cit., 1992, 450. Cf. BLOK, Anton, The Mafia of a Sicilian Village 18601960. A Study of Violent Peasant Entrepreneurs, Oxford, 1974; CACIAGLI, Mario, Democrazia Cristiana e potere nel Mezzogiorno. Il sistema democristiano a Catania, Rimini/Florencia, 1977; CHUBB, Judith, Patronage, Power, and Povery in Soutbern Italy: $A$ Tale of Two Cities, Cambridge (etc.), 1982; GraZIANO, Luigi, Clientelismo e sistema politica. Il caso dell'Italia, Milán, 1980; GriBaUDI, Gabriella, Mediatori. Antropologia del potere democristiano nel Meztogiorno, Turin, 1980; SILVERMAN, Sydel F., «Patronage and Community-Nation Relationships in Central Italy», en: Friends, Followers, and Factions. A Reader in Political Clientelism, ed. por SCHMIDT, Steffen W./GUASTI, Laura/LANDE, Carl H./SCOTT, James C., Berkeley/Los Angeles/Londres, 1977, 293-304.

4 GIORDANO, op. cit., 1992, sobre todo 478-480, 483-512.

Hispania, LVIII/2, núm. 199 (1998) 575-605 
España sólo se haya ocupado de modo intensivo de tales formas de manipulación de los recursos estatales de poder en el contexto del caciquismo de finales del siglo XIX y comienzos del XX ${ }^{5}$. Las investigaciones acerca del caciquismo de la Restauración tienden a suponer que se trata de estructuras surgidas en el contexto de la monarquía constitucional, en lugar de preguntar por el modo como las redes sociales se adaptaron al cambio de las condiciones institucionales y por el papel que desempeñaron en la conformación de éstas ${ }^{6}$. Contados trabajos amplían la perspectiva cronológica hacia el siglo XX o se centran en el Antiguo Régimen ${ }^{7}$. La transformación de las redes en la crisis del Antiguo Ré-

5 Un estadio de las cuestiones planteadas actualmente por la investigación sobre el caciquismo lo ofrecen el volúmen compilado por A. Robles Egea, abajo citado, y ZURITA, Rafael, «La natura del potere politico nella Spagna della Restaurazione (1875-1902): un bilancio storiograficom, Quaderni storici, núm. 87, vol. 29 (1994), 805-827. Cf. CARDESín DÍAZ, José Maria/LAGo PEÑAS, Pedro, «Repensando el caciquismo: Espacio político y agencia social en la Galicia de la Restauracióny, Historia y Critica, 2 (1992), 191-226; CRUZ ARTACHO, Salvador, Caciques y campesinos. Poder politico, modernización agraria y conflictividad rural en Granada, 1890-1923, Madrid, 1994; KERN, Robert W., Liberals, Reformers and Caciques in Restoration Spain 1875-1909, Alburquerque, 1974; MORENO LUZÓN, Javier, «Teoria del clientelismo y estudio de Ia politica caciquils, Revista de Estudios Politicor, núm. 89 (1995), 191-224; idem, «El conde de Romanones y el caciquismo en Castilla (1880-1923)», Investigaciones bistóricas, 16 (1996), 145-166; ROMERO-MAURA, Joaquín, «Caciquismo as a political system», en: GELLNER/WATERBURY, op. cit., 1977, 53-62; SIERRA, María, La familia Ybarra, empresarios y politicos, Sevilla, 1992; TUSELL GÓMEZ, Javier, Oligarquia y Caciquismo en Andalucia (1890-1923), Barcelona, 1976; VAREI.A ORTEGA, José, Los amigos politicos. Partidos, elecciones y caciquismo en la Restauración (1875-1900), Madrid, 1977; YANINI MONTES, Alicia, E/ caciquisme, Valencia, 1984.

6 En este sentido son muy sugerentes las explicaciones acerca de la región de Murcia en: PÉREZ PICAZO, María Tetesa/LEMEUNIER, Guy, «Formes du pouvoir local dans l'Espagne moderne et contemporaine: des bandos au caciquisme au royaume de Murcie (XVe-XIX ${ }^{e}$ siècles)", en: MACZAK, Antoni, ed., Klientelsysteme im Europa der Früben Neuzeit, Múnich, 1988 (=Schriften des Histotischen Kollegs. Kolloquien, 9), 315-341.

7 ROBLES EGEA, Antonio, comp., Politica en penumbra. Patronazgo y clientelismo politicos en la España contemporánea, Madrid, 1996 (las diferentes contribuciones ofrecen un estado de la cuestión). - Sobre el Antiguo Régimen: CONTRERAS CONTRERAs, Jaime, Sotos contra Riquelmes. Regidores, inquisidores y criptojudios, Madrid, 1992; BURGOS ESTEBAN, Francisco Marcos, Los lazos del poder. Obligaciones y parentesco en una élite local castellana en los siglos XVI y XVII, Valladolid, 1994; DEDIEU, Jean-Pierre, «Familia y alianza. La alta administración española del siglo XVIII», en CASTELLANO CASTELLANO, Juan Luis, ed., Sociedad, administración y poder en la España del Antiguo Régimen. Hacia una nueva bistoria institucional. I simposium internacional del grupo P.A.P.E., Granada, 1996, 47-75; CASTEILANO CASTELLANO, Juan Luis/DEDIEU, Jean-Pierre, eds., Réseaux, familles et pownoirs dans le monde ibérique à la fin de l'Ancien Régzme, Parts, 1988; IMÍZCOZ BEUNZA, José Maria, ed., Élates, poder y red social: Las élites del Pais Vasco y Navarra en la Edad Moderna, Bilbao, 1996; MARTÍNEZ MULÁN, José, ed., Instituciones y élites de poder en la Monarquía bispana durante el sigho XVI, Maditd, 1992; BERTRAND, Michel, «Du bon usage des solidarités. Etude du facteur familial dans l'administration des finances de Nouvelle-Espagne, XVII ${ }^{\mathrm{e}}$-XVII ${ }^{\mathrm{e}}$ sièclen, y Schaub, Jean-Frédéric, "Francisco Leitão, commissaire à tout faire», en: DESCIMON, Robert/SCHAUB, Jean-Frédéric/VINCENT, Bernard, eds., Les figures de l'administrateur. Institutions, réseaux, pouvoirs en Espagne, en France et au Portugal, 16e-19e siècle, Paris, 1997, 43-58, 59-74. - Cf. BEIK, William, Ab- 
gimen, que aparece clave para entender la formación del Estado liberal en España, apenas ha suscitado trabajos ${ }^{8}$.

A través del estudio microhistórico de las estrategias empleadas por personas que asumieron en dichos procesos de transformación un papel de intermediario («broken)), el presente artículo quiere no sólo llamar la atención sobre la significación de unos agentes que, dentro de sus comunidades, se especializaron en la mediación de relaciones con el ámbito de los tribunales reales de apelación, en el más amplio sentido -incluyendo por consiguiente las esferas no judiciales de los relatores, escribanos, abogados, etc.-. Se pretende ir más allá de una comprensión ahistórica de la dominación de redes de relaciones personales como una constante antropológica de las sociedades mediterráneas, para, al contrario, interpretar la actividad de estos intermediarios a la vista de los procesos históricos a los que, de ordinario, se suele referir con conceptos como «formación del Estado", «centralización» y «burocratización»" ?. Por encima de valoraciones vinculadas con las imágenes de atraso y de modernización deficita-

solutism and Society in Seventeentb-Century France. State Power and Provincial Aristocracy in Languedoc, Cambridge (etc.), 1985; BnNADUS, Giovanna, A Provincial Elite in Earty Modern Tuscany. Family and Power in the Creation of the State, Baltimore (etc), 1996; GIRY-DELOISON, Charles/METTAM, Roger, eds., Patronages et clientélismes, 1550-1750 (Frante, Angleterre, Espagne, Itakie), Lille/Londres, sin fecha; KETTERING, Sharon, Patrons, Brokers and Clients in Seventeentb-Century France, Nueva York/Oxford, 1986; MOUTOUKIAS, Zacharias, «Réseaux personnels et autorité coloniale: Les négociants de Buenos Aires au XVIIIe siècle», Annales. ESC, 47 (1992), 889-915; PECK, Linda Levy, Court Patronage and Corruption in Early Stuart England, Boston (etc.), 1990.

8 Véase PÉREZ PICAZO/Lemeunier, op. cit., 1988. Sobre los poderes locales y las transformaciones de las tedes clientelates entre élites locales, señores y Monarquía, relacionadas con el reformismo de la segunda mitad del siglo XVIIJ: Windler, Christian, Lokale Eliten, seigneurialer Adel und Reformabsolutismus in Spanien (1760-1808). Das Beispiel Niederandalusien, Stuttgart, 1992 (=VSWG. Beihefte, 105) [traducción castellana: Élites locales, señones, reformistas. Redes clientelares y Monarquía hacia finales del Antiguo Régimen, Sevilla, 1997]; idem, "Clientèles royales et clientèles seigneuniales vers la fin de l'Ancien Régime. Un dossier espagnobs, Annales. HSS, 52 (1997), 293-319; idem, «Beziehungen makeln. Gemeinde und königliche Gerichte in Spanien im ausgehenden Ancien Régimen, Zeitschrift für historische Forscbung, 24 (1997), 53-87. Cf. las contribuciones en GUGGISBERG, Hans R./WINDLER, Christian, Instituciones y relaciones sociales en un municipio de señorio. Estudios sobre la cuestion del poder en Osuna (1750-1808), Sevilla, 1995. - Los siguientes estudios abarcan también la primera mitad del siglo XIX y son por ello de particular interés: Cruz, Jesus, Gentlemen, Bourgeois, and Revalutionaries. Political Change and Cultural Persistence among the Spanish Dominant Groups, 1750-1850, Cambridge (etc.), 1996; IMízcoz BEUNZA, José María, «De la comunidad a la Nación: élites locales, carreras y redes sociales en la España modernay, en: idem, op. cit., 1996, 193-210; PRO RUIZ, Juan, «Las élites de la España liberal: clases y redes en la definición del espacio social (1808-1931)m, Historia Social, núm. 21 (1995), 47-69.

1) Véase por ejemplo MOLAS RIBALTA, Pere, «El Estado absoluto de los Borbones», en: D'AURIA, Elio/CASASSAS YMBERT, Jordi, ed., E/Estado moderno en Italia y Esparia. Ponentias del Simposio Internacional :Organización del Estado moderno y contemporáneo en Italia y Españan, Barcelona, 1993, 49-61. Para una síntesis crítica hacia este tipo de planteamientos, véase FERNÁNDEZ AL. BALADEJO, Pablo, «La Monarquía de los Borbones», en: idem, Fragmentos de Monarquia. Trabajos de bistoria politica, Madrid, 1992, 353-454.

Hispanitu, LVIII/2, núm. 199 (1998) 575-605 
ria, cabe preguntarse por las formas de manipular los recursos de poder estatal que, en la crisis del Antiguo Régimen, acuñaron en España una estatalidad peculiar ${ }^{10}$.

Desde la historia del Derecho y reanudando en particular con las reflexiones de O. Brunner ${ }^{11}$, A. M. Hespanha y B. Clavero han formulado una crítica radical del análisis de las monarquías del Antiguo Régimen en los términos de una prehistoria del Estado liberal del siglo XIX ${ }^{12}$. Sin embargo, su crítica se impone dificilmente a la investigación prosopográfica, que, en vez de elaborar el objeto de investigación a través de la observación de la praxis social, parte de las estructuras institucionales formales (los Consejos, las Audiencias y Chancillerías, el cabildo de una ciudad ...), privilegiando una visión estatalista del poder y llegando a una imagen anacrónica de "carreras" burocráticas ${ }^{13}$. Con estas premisas, la influencia, a menudo especialmente grande, de jueces que durante muchos años - y en ocasiones dutante toda su vida - ejercieron el mismo oficio, resulta incomprehensible ${ }^{14}$. La prosopografía de los tribunales se centra en los jueces, mientras que el personal no judicial de los juzgados - junto con los relatores y fiscales, tan importantes para el desarrollo del proceso, también los escribanos de Cámara-, beneficia tan sólo de un interés marginal ${ }^{15}$. Aún me-

10 Cf. la introducción de Stuart WOOLF a la obra editada por êl: Espaces at familles dans l'Europe du Sud à l'âge moderne, París, 1993, 7-28.

11 BRUNNER, Otto, Land und Herrschaft. Grundfragen der territorialen Verfassungsgescbichte Österreichs im Mittelatter, Wien, ${ }^{4} 1959$ (1. ${ }^{2}$ edición: 1939), y los ensayos reunidos en: idem, Neue Wege der Veffassungs- und Sorialgeschichte, Göttingen, 21968 (1era. edición: 1956).

12 HeSPANHA, Ántónio Manuel, As vésperas do Leviathan. Instituifóes e poder politico. Portugal séc. XVII, 2 volúmenes, Lisboa, 1986; idem, Poder e Instituigöes no Antigo Regime. Guia de Estudo, Lisboa, 1992; idem, "Justiça e administração entre o Antigo Regime e a Revoluçãom, en el volumen por él editado: Justiça e litigiosidade: Histótia e prospectiva, Lisboa, 1993, 381-468 (citado: 1993a); idem, La gracia del Derecho. Economia de la cultura en la Edad Moderna, Madrid, 1993 (citado: 1993b); idem, Panorama bistórico da cultura juridica europeia, Lisboa, 1997. CLAVERO, Bartolomé, "Institución política y derecho: acerca del concepto historiográfico de «Estado Moderno», Revista de Estudios Politicos, núm. 19 (nueva época) (enero-febrero de 1981), 43-57; idem, Tantas personas como Estados. Por una antropologia política de la bistoria europea, Madrid, 1986; idem, Antidora. Antropología católica de la economia moderna, Milán, 1991 (=Per la storia del pensiero giuridico modemo, 39). Un estado crítico de la cuestión del «Estado» en: SCHAUB, Jean-Frédéric, «La penisola iberica nei secoli XVI e XVII: La questione dello Statom, Studi Storici. Rivista trimestrale dell'Istituto Gramsci, 36 (1995), 9-49.

13 Véase, por ejemplo, MOLAS RIBALTA, Pere, ed., Historia social de la administración española. Estudios sobre los sighas XVII y XVII, Barcelona, 1980; idem, «Consejos y Audiencias», Studia Historica. Historia Moderna 15 (1996), 9-21; CASTELLANO CASTELLANO, Juan Luis, «La cartera burocrática en la España del siglo XVIII", en CASTELLANO CASTELLANO, op. cit., 1996, 25-45.

14 Acerca de la posición de tales jueces en los complejos entramados de relaciones, véase la importante contribución de DEDIEU, op. cit., 1996.

$15 \mathrm{CE}$, por ejemplo, CANET APARISI Teresa, La magistratura valenciana (s. XVI-XVI), Valencia, 1990.-T. Herzog, con su tesis sobre la justicia penal en Quito, y J. M. Scholz, en un artículo sobre los relatores, ponen en evidencia hasta qué punto una prosopografia limitada a los jueces pasa por alto aspectos fundamentales de las instancias judiciales. Gracias a este tipo de 
nos se sabe de las redes tejidas entre aquellos que disponían de una posición formal en un tribunal, los que vivían de sus contactos cotidianos con ellos (los abogados ${ }^{16}$, los procuradores y los agentes de pleitos) y las partes implicadas en los juicios. Sólo se pueden adivinar las dificultades prácticas a las cuales tenían que hacer frente aquellos que se dirigian a un tribunal ${ }^{17}$ como así también el papel que asignaban a las instancias judiciales en la solución de los conflictos.

Con la originalidad de su crítica de la historiografía del «Estado moderno» contrasta el análisis que hace $\mathrm{B}$. Clavero de las transformaciones del siglo XIX. Basándose en una lectura de textos producidos por las mismas instituciones y dando por sentada la trascendencia social de la revolución jurídica liberal, B. Claveto pasa por alto los límites de estos cambios, es decir la importancia persistente de las redes de parentesco, amistad y patronazgo como dispositivos centrales de los procesos de decisión política ${ }^{18}$. El tipo ideal weberiano del Estado parece entonces surgir como modalidad dominante de estructuración de las relaciones sociales. La abundante historiografía sobre el caciquismo de la Restauración contradice esta visión de la revolución liberal, como también lo hace un proyecto aún inconcluso dirigido por J.-M. Scholz sobre el mundo judicial. En efecto, en las carreras de los jueces, las redes personales siguieron dominando en el siglo XIX sobre las normas legales, que parecían favorecer la profesionalización del campo judicial ${ }^{19}$.

aproximaciones, se comprende por qué, para favorecer el curso de sus pleitos, las partes se dirigían tanto a los relatores o escribanos de Cámara como a los jueces (HERZOG, Tamar, La administración como un fenómeno social la justicia penal de la ciudad de Quito (1650-1750), Madrid, 1995; SCHOLZ, Johannes-Michael, wDie Augen der Magistratur. Zur richterlichen Arbeitsteilung spanischer Justiz in der Moderne», Ius Commune, 19 (1992), 95-168 (citado: 1992a)). En el caso de los fiscales, no habría que pensar tanto en un resumen de sus competencias jurídico-formales ni en una recopilación de sus informes (como lo realiza CORONAS GONZÁLEZ, Santos Manuel, Ilustracion y Derecbo. Los fiscales del Consejo de Castilla en el siglo XVIII, Madrid, 1992), cuanto en un análisis de su actividad en el contexto del proceso.

16 Contamos todavía con pocos trabajos sobre los abogados, en particular para el siglo XVIII y la primera mitad del siglo XIX: AMELANG, James S., Honored Citizents of Barcelona. Patrician Culture and Class Relations (1490-1714), Princeton, 1986, sobre todo 68-73, 110-126; idem, «Barristers and Judges in Early Modern Barcelona: The Rise of a Legal Elite», $A H R, 89$ (1984), 1264-1284; KAGAN, Richard L, Lawsuits and Litigants in Castile, 1500-1700, Chapel Hill, 1981; iden, Students and Society in Early Modern Spain, Baltimore, 1974.- Carecemos de estudios que puedan compararse con la biografia colectiva de Prest de la abogacía inglesa o con el estudio de $\mathrm{H}$. Siegrist acerca de los abogados en Alemania, Italia y Suiza (PREST, WILFRID R., The Rise of the Barristers. A Social History of the English Bar 1590-1640, Oxford, 1986; SiEGRIST, Hannes, Advokat, Bürger und Staat. Eine vergleichende Geschichte der Recbtsanwülte in Deutschland, Italien und der Schwein (18. - $20 \mathrm{Jb}$.), 2 volúmenes, Ftancfort del Meno, 1996 (=Ius Commune. Sonderheft). Cf. KARPIK, Lucien, Ler apocats. Entre l'Etat, le public et le marché, XIIIe-XX siècles, París, 1995.

17 Para los siglos XVI y XVI, cf. los trabajos ya citados de R. L. Kagan.

18 Cf. las conclusiones de CLAVERO, op. cit., 1986.

19 Cf. SCHOLZ, Johannes-Michael, «Amt als Belohnung. Eine spanische Justizkarriere am Ende des Ancien Régimes, Ius Commune, 18 (1991), 51-147; SCHOLZ, Johannes-Michael, et al., "A la recherche de la justice espagnole: le groupe SPANJUS», y SCHOLZ, «La compétence judi-

Hiptania, LVIII/2, nủm. 199 (1998) 575-605 
A causa de la escasa presencia inmediata de la buroctacia real ${ }^{20}$, en particular en los pueblos de señorío, - pese a las reformas administrativas que se centraban aún en el ámbito fiscal-y por la complejidad de los procedimientos burocráticos, la centralización formal, aunque limitada, de las competencias resolutorias dio lugar, a partir del siglo XVIII, a una nueva demanda de gestores e intermediarios especializados y a nuevas dependencias respecto de patronos que controlaban las relaciones entre los municipios y los agentes del poder que residian fuera de ellos ${ }^{21}$.

En un estudio publicado en 1977 acerca de Los amigos politicos, J. Varela Ortega ya apuntaba al papel de unos especialistas que, aunque necesitados materialmente, gracias a su capacidad de establecer, mediar y manipular relaciones ganaron una influencia política considerable ${ }^{22}$. Una historia social de talante economicista, orientada predominantemente a la cuantificación de los recursos materiales, sigue descuidando sin embargo los factores inmateriales de diferenciación social. Los impulsos que podrían haber llegado, por ejemplo, de la $m i$ crostoria italiana - piénsese en el estudio de G. Levi sobre La berencia inmaterial - apenas se han aprovechado ${ }^{23}$.

El presente artículo no puede ser sino un estudio preliminar y parcial para una historia social de la mediación a finales del Antiguo Régimen. Reflexiones como las elaboradas en las ciencias sociales, de procedencia predominantemente anglosajona, ofrecen un punto de partida válido para una consideración histórica centrada en el ámbito ibérico del papel de los intermediarios o brokers dentro de las redes sociales ${ }^{24}$. Estos brokers median contactos con personas

ciaire. Sur l'histoire contemporaine de la justice espagnole", en idem, ed, El tercer poder. Hacia una compransión bistórica de la justicia contemporánea en España, Francfort del Meno, 1992 (=Rechtsprechung, 5) (citado: 1992b), 67-91, 297-348; SCHOLZ, «La justice espagnole en cours de classement. Critique de la prosopographie des institutions», Ius Commtune, 22 (1995), 241-270; idem, «Situativ beobachten und opak kommunizieren. Wahrnehmungen an einer hochvemetzten Gesellschaft), in: SCHOLZ, Johannes-Michael/HERZOG, Tamar, eds., Observation and Communitation: The Construction of Reakties in the Hispanic World, Francfort del Meno, 1997 (-Ius Commune. Sonderhefte 101), 3-110.

20 Véase DEDIEU, Jean-Pietre, «La haute administration espagnole au XVIII ${ }^{e}$ siècle. Un projets, en: SCHOLZ, op. cit., 1992b, 51-65.

21 Véase BLOK, op. cit., 1974 (sobre los mafiosos sicilianos de los siglos XIX y XX como intermediarios políticos) SILVERMAN, op. cit., 1977, 294, 297-300 (sobre patrones como brokers en una comunidad umbria); PITT-RIVERS, Julian A., The People of the Sierra, Chicago/Londres, ${ }^{2} 1961$ (primera edición: 1954), 141, 154-156 (según Pitt-Rivers, en el pueblo andaluz de Grazalema, el patronazgo vinculaba la autoridad del Estado con la red de relaciones vecinales).

22 J. VaRELA ORTEGA, op. cit., 1977, 364-369, 436-437.

23 Levi, Giovanni, L'eredità immateriale. Carriera di un esorcista nel Piemonte del Seicento, Turín, 1985. Cf. RAGGIO, Osvaldo, Faide e parentele. Lo stato genovese visto dalla Fontanabuona, Turin, 1990.

24 Además de la bibliografía citada en las notas 1 y 3 , véanse BOISSEVAIN, Jeremy, Friends of Friends. Networks, Manipwlators and Coalitions, Oxford, 1974, 147-169; EISENSTADT, S.N., RONIGER, L., Patrons, clients and Friends. Interpersonal Relations and the Structure of Trust in Society, Cam- 
que controlan ellas mismas los recursos requeridos, o que al menos pueden por su parte entablar contactos ulteriores ${ }^{25}$. Se encargan de velar por los puntos de contacto críticos entre un sistema local y otros más amplios ${ }^{26}$. Su posición depende de la mayor importancia que tengan para los interesados las relaciones que ellos puedan mediar, así como de la ausencia de vías alternativas de comunicación ${ }^{27}$.

En las correspondencias de las administraciones nobiliarias, que acompañaban los pleitos sobre derechos señoriales ante los tribunales reales, aparecen intermediarios, que si bien ellos mismos sólo disponían de tecursos materiales insignificantes, sus actividades eran seguidas con suma preocupación y minuciosidad por parte de los administradores, pues merced a su saber y sus relaciones habian alcanzado una influencia considerable.

En la primera parte, describiremos la trayectoria de uno de estos agentes de pleitos, Gabriel Valverde Ladrón de Guevara, de Priego de Córdoba. Se trata de un intermediario de situación material modesta, cuya posición dependía de sus telaciones en el municipio, de su experiencia y de sus contactos dentro de la Real Chancillería de Granada, así como de la posibilidad de dedicar de modo constante su tiempo a tal actividad ${ }^{28}$. Él mismo era cliente de vecinos poderosos, pero ganó ante ellos un campo de acción considerable. Enfocando los conflictos judiciales entre los notables de una agrociudad (agrotown) andaluza - Priego de Córdoba - y su señor —el duque de Medinaceli-, se rastrearán las posibilidades de ascenso social que ofrecía la mediación de relaciones entre los tribunales y los legos en materia de Derecho. Trataremos de responder a la pregunta ¿en qué medida también personas ticas e influyentes a nivel local recurrían en sus relaciones con un tribunal real a gestores e intermediarios especializados, porque el éxito en un pleito requería conocimientos y experiencias de los que ellos carecían?

Basados en la descripción de la trayectoria del intermediario Gabriel Valverde Ladrón de Guevara, de su éxito inicial y posterior incapacidad de consolidar la posición alcanzada, los capítulos siguientes proponen una interpretación del cambio político a finales del Antiguo Régimen desde la perspectiva del análisis de redes. Preguntamos por el papel de los intermediarios en la configuración

bridge (etc.), 1984; SCHMIDT, Steffen W., «The Transformation of Clientelism in Rural Colombias, en: Friends, Followers, and Factions, op.cit., 1977, 305-322; idem, «Patrons, Brokers, and Clients: Party Linkages in the Colombian Systemy, en: LAwson, Kay, ed., Political Parties and Linkage. $A$ Comparative Perspective, New Haven/Londres, 1980, 266-288; SCOT1, James C., "Patron-Client Politics and Political Change in Southeast Asian, en: Friends, Followers, and Factions, op. cit., 1977, 123-146, sobre todo 126-128; WOLF, Etic R, uAspects of Group Relations in a Complex Society: Mexicon, American Anthropologist, 58 (1956), 1065-1078.

25 BOISSEVAIN, $o p$. cit., 1974, 147-148.

26 «stand guard over the critical junctures or synapses of relationships which connect the local system to a larger whole) (WOLF, op. cit., 1956, 1075)).

27 SILVERMAN, op. cit., 1977, 294.

28 Véase BOISSEVAIN, op. cit., 1974, 153-158.

Hitpantia, LVill/2, núm. 199 (1998) 575-605 
de un espacio político que trascendía el ámbito local. A este respecto, el caso de Priego permite formular algunas conclusiones acerca del ascenso de una familia que se encontraba entre los comitentes de Gabriel Valverde y tendrá en el siglo XXX y XX un papel importante a nivel nacional, los Alcalá Zamora.

Si dirigimos nuestra mirada a un intermediario especializado, el interés se centra, por un lado, en sus estrategias en el trato con la Real Chancillería, $y$, por otro, en su posición dentro de las estructuras del poder de un pueblo de señotío. Con ello, deben exponerse las interacciones entre el modo de funcionamiento de las redes de relaciones en el ámbito local, el desarrollo de una cultura jurídica más profesionalizada y la creciente importancia de las instancias judiciales dependientes de la Corona en la sociedad española del siglo XVIII. Para rastrear estos influjos recíprocos resulta especialmente adecuada una perspectiva local, pues desde ella se reconoce más nítidamente la complementariedad entre el potencial económico, las redes de relaciones (parentesco, amistad, patronazgo), el saber especializado y los recursos del poder institucional. La perspectiva microhistórica no implica en este caso la renuncia a una explicación más general, sino que debe posibilitar la descripción de redes de relaciones, experiencias y formas de comportamiento que quedan encubiertas para el habitual acceso macrohistórico, aunque sean de central significación para la conformación de una estatalidad peculiar. Parafraseando la precisa formulación de G. Levi, no se trata de contemplar cosas pequeñas, sino de mirar «en to pequeño' ${ }^{29}$, para comprender, en particular, las modalidades de la integración de las comunidades locales dentro del incipiente marco nacional y sus consecuencias para la configuración de este espacio político.

El intermediario Valverde no logró consolidar la posición alcanzada. Las redes de relaciones supralocales serán dominadas por algunos de sus más importantes comitentes. Esto conduce a la pregunta de por qué éstos habían consentido en un primer tiempo en depender de los servicios de tal intermediario. Hay que mostrar cómo en un contexto de cambio un hombre de condición modesta era capaz de ganar una influencia considerable como gestor e intermediario. También habrá entonces que rastrear los motivos de su posterior zozobra, y preguntarse por qué el campo de acción que en un principio le parecía destinado fue en última instancia apropiado por algunos de sus comitentes.

\section{LA TRAYECTORIA DE UN INTERMEDIARIO: GABRIEL VAIVERDE LADRÓN DE GUEVARA}

Los pleitos a los que nos referimos se originaron en Priego, una agrociudad situada al sur de la actual provincia de Córdoba. Señores de la villa como mar-

29 Citado por MEDICK, Hans, «Mikro-Historie», en: SCHULZE, Winfried, ed., Sozialgeschichte, Alltagsgeschichte, Mikro-Historie. Eine Diskussion, Göttingen, 1994, 40-53, cita: 40. Para una reflexión sobre el análisis mictohistórico, véanse las demás contribuciones de dicho volúmen y, más recientemente: REVEL, Jacques, ed., Jeux d'échelles. La micro-analyse à l'expérience, París, 1996. 
queses de Priego, los duques de Medinaceli poseían según el Catastro de Ensenada en superficie un $17,1 \%$ de las tierras del término municipal, en producto un $18,2 \%{ }^{30}$. Este patrimonio señorial se situaba en Priego en el centro de las discusiones sobre la reincorporación del señorío. Contrariamente a los demás señorios cordobeses de la Casa de Medinaceli, aquí se demandaba el dominio solariego de la Casa. En ausencia de títulos de propiedad, los vecinos acusaban a la Casa de haber usurpado dichas tierras. La sentencia definitiva de 1836, favorable a la Casa, se basaba en un pretendido derecho de conquista en esta zona fronteriza con el reino de Granada ${ }^{31}$.

Comparado con el producto de las tierras, estimado en el Catastro de Ensenada en 342.436 reales de vellón, los derechos recaudados en concepto de monopolios y estancos (3.271 reales) y en el ejercicio de la jurisdicción (3.285 reales, sobre todo por el repartimiento de aguas) eran insignificantes. El arrendamiento de oficios, en particular de la correduría de seda y tafetanes valorada en el Catastro en 10.285 reales, tenía de igual modo una importancia aparentemente reducida en el conjunto de las rentas percibidas por la Casa en Priego. Aún teniendo en cuenta los ingresos de las instalaciones protegidas por el monopolio señorial (hornos, molinos, mesones: 31.217 reales), el peso económico de los estancos parece haber sido limitado ${ }^{32}$.

La tesistencia de los vecinos contra estos detechos de la Casa no se explica tanto por su nivel cuantitativo como por las posibilidades de control político y económico que daban a la Casa. Así, la tegalía de nombrar los cargos municipales, aparentemente sin valor económico, eta un aspecto central del poder señoríal. En la segunda mitad del siglo XVIII, la oposición contra el ejercicio de estos derechos se manifestó en los numerosos pleitos seguidos por vecinos de la villa contra la Casa ducal. Menos que en sentencias definitivas, la fuerza de esta oposición quedó reflejada en las concesiones que tuvo que hacer la Casa, abandonando parcelas de su posición privilegiada. Así, por ejemplo, la cuota de la Casa en el repartimiento de Paja y Utensilios aumentó de un modesto $8,53 \%$ en 1772 a un $23,23 \%$ en $1807^{33}$.

A finales del siglo XVIII (1786/87), casi el 80\% de sus más de 13.000 habitantes vivían en el núcleo de la Villa, mientras que el resto se dispersaba por varias aldeas, dependientes de su jurisdicción ${ }^{34}$. La fuerte concentración de la población, que dejaba amplios espacios abiertos y apenas colonizados, y el mal estado de los caminos ${ }^{35}$ fomentaban en general la orientación de los andaluces

30 Se trataba de valores cercanos a los promedios del Marquesado (cf. ESTEPA GIMÉNEZ, Jesús, El Marquesado de Priego en la disolución del régimen señorial andaluz, Córdoba, 1987, 141).

31 ESTEPA GIMÉNEZ, op. cit., 1987, 245-247,315-323.

32 ESTEPA GIMÉNEZ, op. cit., 1987, 249, 252-253.

33 AMP [=Archivo Municipal, Priego de Córdoba], leg. 457-1, 531-1+2, 385-2.

34 Censo de 1787 «Floridablanca», editado por el Instituto Nacional de Estadística, vol. 1: Comunidades Autónomas Meridionales, Madrid 1986, 489-490.

35 CE. MADRAZO MADRAZO, Santos, El sistema da comunicaciones en España, 1750-1850, vol. 1, Madrid, 1984; sobre Andalucía: Jurado Sánchez, José, Los caminos de Andalucia en la segunda mitad del siglo XITII (1750-1808), Córdoba, 1988.

Hispantia, LVIII/2, núm. 199 (1998) 575-605 
hacia su patria chica. Tanto en lo económico como en lo político, la Andalucía de fines del siglo XVIII estaba poco integrada. Según la precisa formulación de un autor anónimo contemporáneo, "cada lugar vive, por decirlo así, aislado, obra para $s i, y$ forma una provincia separada», ${ }^{36} \mathrm{La}$ distancia geográfica respecto de las instancias superiores contribuía a que las relaciones con los poderosos que residian fuera de los municipios fuetan capital de unos pocos. El intendente residía en Córdoba, que quedaba a unos 100 kilómetros, y la Real Chancillería, que era el tribunal real de apelación competente en la mayotía de los casos, se encontraba en Granada, aproximadamente a unos 80 kilómetros. Hasta la administración señorial superior o Contaduría en Montilla había que recorrer aún unos 60 kilómetros.

El término de Priego se emplaza en el ámbito de la cordillera subbética, entre la cuenca del Guadalquivir y el Mediterráneo. Esta zona está claramente diferenciada en sus condiciones naturales y en lo socioeconómico respecto de la cuenca del Guadalquivir, conformada por tierras de secano explotadas en latifundios. En comparación, el latifundio está en Priego más parcelado ${ }^{37}$, pero los terrenos son por lo general de peor calidad, la agricultura más extensiva y la importancia de la ganadería mayor. Un contraste muy ostensible con las tierras de secano ofrecen en Priego los cultivos de regadío a lo largo de los cursos de agua y en el ámbito de las fuentes kársticas ${ }^{38}$. De estos recursos hidráulicos, relativamente abundantes, dependía también la artesanía de la seda de Priego, que llegó a ser importante durante el Antiguo Régimen ${ }^{39}$. Pese a las posibilidades de subsistencia, más diversificadas en comparación con las agtociudades de la cuenca del Guadalquivir, se trataba de una sociedad muy desigual en cuanto al reparto de los recursos: si se considera la concentración de las contribuciones (repartimientos de Paja y Utensilios), resultan también en Priego valores muy altos (coeficientes de concentración entre 0,86 y 0,88 en los años 1772 , $1781,1790,1799$ y 1807). Un pequeño grupo de hidalgos y plebeyos, distinguidos con el tratamiento de «don», apenas constituía el $4,25 \%$ de los vecinos varones seculares, pero aportaba un $46,91 \%$ de los impuestos ${ }^{40}$. Se trataba de una élite de notables cuya posición, determinada más por los recursos económicos (la explotación de la tierra, pero también las actividades relacionadas con la artesanía de la seda) o la cualificación personal (por ejemplo en el caso de los abogados) que por el origen familiat, se caracterizaba por el respeto y la influencia que gozaban en las redes de relaciones sociales, mientras que los privi-

36 Descripción de un Cortijo del Reino de Sevilla, sin fecha (segunda mitad del siglo XVIII, después de la expulsión de los jesuitas) (FUE -AC [=Fundación Universitaria Española, Madrid- Archivo de Campormanes], 24-19).

37 CE. MATA OLMO, Rafael, Pequeña y gran propiedad agraria en la depresión del Guadalquivir, vol. 1, Madrid, 1987, 207, 215-221.

38 ESTEPA GIMÉNEZ, op. cit., 1987, 111-120, 181-187; ORTEGA ALBA, Francisco, E/ Sur de Córdoba. Estudio de grografía agraria, vol. 2, Córdoba, 1975, 22-30.

39 ESTEPA GIMÉNEZ, op. cit., 1987, 193-198, 211-212.

40 Cf. WINDLER, op. cit., 1992, 74. 
legios legales se desvanecían ${ }^{41}$. Los notables de Priego mantuvieron frente a su señor jurisdiccional un campo de acción considerable, que logtaron ampliar en la segunda mitad del siglo XVIII.

En las últimas décadas del siglo XVIII fueron cuestionados los derechos de la Casa de Medinaceli por parte de una facción de notables que se volvió contra el cabildo municipal y la administración señotial, que lo nombraba y protegía. Al principio, los pleitos ante la Chancillería de Granada afectaban solamente a ciertos derechos particulares de la Casa ducal: la superioridad del alcalde mayor señorial sobre los alcaldes ordinarios o jueces nombrados por el Concejo, los estancos, las Alcaidías del Agua, responsables de su distribución, el control de calidad de los tejidos de seda fabricados en Priego, o el poder de disponer de los pesos y medidas del pósito municipal, así como una parte de los derechos ducales sobre la tierra. Pero en 1785 las demandas se extendieron al señorio como tal, con la particularidad, arriba mencionada, de incluir expresamente el dominio solariego de la Casa, la cual distinguía el pleito de Priego de los pleitos de reincorporación de otros señoríos cordobeses de la Casa de Medinaceli. No obstante, en los años 1780 y 1790 , la oposición antiseñorial de los notables se vertebraba a partir de una lógica clientelar. Para los contrarios de la administración ducal se trataba de ampliar su campo de acción dentro de las estructuras del señorío, y en particular, de ganar mayor consideración en el nombramiento del cabildo por el duque ${ }^{42}$.

No es éste el lugar para estudiar más detenidamente los trasfondos y el contenido de las demandas. Más bien hay que aclarar en qué medida se vinculaba con estos conflictos el ascenso de familias o de personas particulares que, merced a sus conocimientos y sus relaciones, pudieron sacar de ellos un partido provechoso. Para este fín, con la correspondencia de la Mayordomía de la Casa de Medinaceli en Priego, de la Contaduría de Montilla, del agente en Granada y de la administración ducal en la Corte, se dispone de una documentación que permite conocer muchos aspectos de un campo de acción siempre informal por definición, y que, al menos para la investigación del ámbito ibérico, ha permanecido hasta ahora casi oculto. Estas correspondencias ponen en el centro de atención el comportamiento cotidiano de las partes, así como de sus asesores.

Ante todo llama la atención que entre los principales instigadores de los pleitos se encuentren un don Francisco Ubaldo Alcalá Zamora y su hermano,

41 Entendemos el concepto de notables a partir de la definición que da WEBER de los "Honoratioren» (véase Weber, Max, Wirtschaft und Gesellschaft. Grundriss der verstehenden Soziologie, Tübingen, ${ }^{5} 1972$ (primera edición: 1922), 170-71, 546-47, 582). El concepto ha sido consagrado en la historiografia francesa por los trabajos de Tudesq (Tudesq, André-Jean, Les grands notables en France (1840-1849). Etude bistorique d'une psychologie sociale, 2 tomos, París, 1964 (=Publications de la Faculté des Lettres et Sciences Humaines de Paris, série: Recherches 20 21)) y Bergeron/Chaussinand-Nogaret (BERGERON, Louis, CHAUSSINAND-NOGAREI', Guy, Les («masses de granit): cent mille notables du Premier Empire, París, 1979).

42 WINDLER, op. cit., 1992, 168-170, 374-375, 378-379.

Hispania, LVIII/2, núm. 199 (1998) 575-605 
el presbítero don José Pío Alcalá Zamora, antepasados de don Niceto Alcalá Zamora, nacido igualmente en Priego, que habria de ser presidente de la República española desde 1931 hasta 1936. A finales del siglo XVIII, los hermanos Alcalá Zamora estaban aliados con dos sacerdotes poderosos a nivel local, José Ruiz de Tienda y Antonio Lozano y Valenzuela. El mayordomo del duque en Priego juzgaba en 1787 que estos cuatro (sujetos con fondos» financiaban como "acérrimos contranios de la Casas los pleitos contra aquella ${ }^{43}$. En el siglo XIX, la familia Alcalá Zamora desempeñaría un papel importante en la política española, con el respaldo de su base de poder en Priego y sus alrededores. Así, don Pedro Alcalá Zamora, uno de los hijos de don Francisco Ubaldo, partícipe de los procesos de los años 80 del siglo XVIII, llegaría a ser diputado provincial de Córdoba en 1820 y más tarde senador del Reino, tras la muerte de Fernando VII y el restablecimiento del sistema constitucional, diputado a Cortes y jefe político de Sevilla.

Los Alcalá Zamora eran una de aquellas familias andaluzas que en la segunda mitad del siglo XVIII y a lo largo del XIX supieron mejorar de modo decisivo su posición económica como labradores, sus redes de relaciones - locales y, en medida creciente, supralocales-, su capital de saber jurídico, así como su posición y prestigio estamental. El ascenso estamental lo simbolizó en los primeros años del siglo XIX el reconocimiento como hidalgos por parte de la Chancillería de Granada, sobre la base de un expediente que habían podido componer gracias a su influencia en la villa de Priego, frente a una situación jurídica claramente adversa a sus pretensiones ${ }^{44}$.

La historia de esta familia de parvenus, durante el siglo XIX, da testimonio de la capacidad de convertir en poder político un capital inmaterial de saber y de relaciones que se extendian más allá del municipio. A finales del XVIII, los Alcalá Zamora no disponían todavía de apoyos familiares en los tribunales superiores. A falta de disponer de parientes en Granada, en sus pleitos contra la Casa ducal ante la Chancillería tenían que recurrir a los servicios de intermediarios, los cuales alcanzaron a su vez respecto de sus comitentes un margen de maniobra relativamente amplio, que habrian de aprovechar en parte en perjuicio de aquellos. En los años ochenta y principios de los noventa, el maestro de boticario Gabriel Valverde Ladrón de Guevara fue el más importante de estos intermediarios, a quien trataremos más de cerca en lo que sigue 45. A partir de la correspondencia de la Casa de Medinaceli, se puede mostrar en este caso de qué manera, pese a la falta de bienes materiales, pero gracias a su habilidad como intermediario, le fue posible ganar una influencia considerable, mejorar su prestigio social y, en cierta medida, también su situación material.

43 José de Toro Carrillo a José Mariano Rodríguez de Mora, contador de Montilla, Priego, 27.11.1787 (ADMC [=Archivo Ducal de Medinaceli], Contaduría de Montilla, s.i. [= sin inventariat]).

44 Cf. WiNDIER, op. cit., 1992, 102-104.

45 C. WINDLER, op. cit., 1992, 300-303. 
A mediados del siglo XVIII, la madre de Gabriel Valverde Ladrón de Guevara llevaba como viuda una tienda de jabón. Ni ella ni su hijo, quien todavía era menor de edad, poseían por aquel entonces bienes inmobiliatios ${ }^{46}$. Tal impresión de condiciones materiales muy modestas la procura también el testimonio coincidente de los repartimientos de impuestos ${ }^{47}$. Sin embargo, tanto la madre con su tienda de jabón, como el hijo en tanto que boticario, debieron conocer a muchas personas en el marco del municipio, un buen punto de partida para la especialización de Valverde como gestor e intermediario. Sin descuidar su actividad, madre e hijo pudieron entablar relaciones a las que Gabriel Valverde Ladrón de Guevara recurríría. Con estas posibilidades de contactos fueton de la mano la voluntad y la habilidad de Valverde para especializarse en la mediación de relaciones sociales ${ }^{48}$.

Un hito en su vida lo marcó en este sentido su elección como diputado del Común en el año 1783, cargo que habría de ejercer hasta finales de los ochenta merced a la prolongación del tiempo de ejercicio del cargo, en principio de dos años, decretada por el Consejo de Castilla ${ }^{49}$. Los cargos de diputados del Común fueron creados en 1766 por el Consejo de Castilla y agregados a los cabildos. En su elección podían participar todos los vecinos varones contribuyentes. Igual que al personero del Común, elegido también por los vecinos, el Consejo de Castilla venía a facilitarles el acceso a los tribunales reales metced a la reglamentación de que los costes de los pleitos quedaran cubiertos, bajo determinados supuestos, con los medios de los Propios municipales. En el caso de Priego, los vecinos contratios a la Casa de Medinaceli, propietaria de la jurisdicción, aprovecharon las posibilidades brindadas por esta reforma para procurarse un fundamento institucional para su actuación contra el gobierno municipal y la administración ducal.

El diputado del Común Valverde actuaba en servicio y con el apoyo material de sus poderosos protectores y comitentes ${ }^{50}$. Sus adversarios insistian en presentarlo como un mero «testaferro» que, por su pobreza y baja posición social, no representaba nada. Pero entonces se enredaban en flagrantes contradicciones, cuando, por un lado, subrayaban su dependencia económica, mientras que, por otro lado, lo declaraban el perturbador del pueblo, por cuya culpa Priego se habria llenado de "parcialidades y bandos», y que constantemente estaría gestionando pleitos y recursos, de tal modo que apenas quedaría algún tribunal que no se viera obstaculizado por ellos ${ }^{51}$.

\footnotetext{
46 AHPCO [=Archivo Histórico Provincial, Córdoba], libro 550, Fol. 135v.

47 Repartimiento de Paja y Utensilios 1772: 0 reales; 1781: 4 reales $(77 \%$ de la contribución media de todos los vecinos vatones seculares); 1790 : 2 reales ( $32 \%$ de la contribución media de todos los vecinos varones seculares); $1799: 8$ reales ( $123 \%$ de la contribución media de todos los vecinos varones seculares) (AMP, leg. 457-1, 531-1+2, 385-2).

48 Cf. Boissevain, op. cit., 1974, 156-158.

49 AMP, leg. 298-2 y Actas Capitulares, 1786 y sigs.

50 Entre otros, Juan Antonio de Reyna y Garcia al duque, fechada en Priego, el 1 de agosto de 1785: (por él no podía hacer nada, por ser un infeliz» (ADMC, Contaduría de Montilla, s.i.).

51 Cabildo 12 de diciembre de 1785 (AHN [=Archivo Histórico Nacional, Madrid, Consejos, leg. 897-11, Fol. 5r, cf. 21r-22v).
}

Hipania, JVIII/2, núm. 199 (1998) 575-605 
De hecho, a lo largo de los años Valverde había acumulado todo un capital inmaterial de saber y relaciones. Que las declaraciones acerca de la pobreza y la dependencia de Valverde respecto de sus comitentes no se ajustaban a esta posición, lo pone de manifiesto el comportamiento de la administración ducal. Aunque la correspondencia acerca de Valverde se mantiene en un tono de tajante distanciamiento estamental, resulta evidente que la administración ducal estimaba mucho el valor de sus dotes profesionales, y era del parecer de que Valverde se había ido convirtiendo paulatinamente en una figura clave del sistema de poder local. El provecho que pudo obtener del proceso sobre la jurisdicción señotial, no se encontraba en el mismo objeto del pleito, que ante todo interesaba a los vecinos «acaudalados o hacendados», sino en las posibilidades que su papel de «agente de pleitos ajenos» le brindaba ${ }^{52}$. Como tal ganó asimismo prestigio social. No sin reparos llegó a ser tratado de «don», tratamiento que expresaba una consideración social del honor ${ }^{53}$.

La posición de Valverde quedaba determinada por sus conocimientos de los expedientes de los pleitos y su experiencia, acumulada durante años, de la praxis de administraciones y tribunales, así como por sus relaciones dentro del municipio y en torno a la Chancillería. En 1790, en su calidad de apoderado de los contrarios, pasaba desde hacía ya años la mayor parte de su tiempo en Granada, y apenas rara vez regresaba a Priego para unos pocos días ${ }^{54}$. Entre el «capital de su negocio" se encontraba una vasta documentación que él había reunido en su casa ${ }^{55}$. Valverde se había convertido ante todo en un especialista de las prácticas sociales de los tribunales y las administraciones. En cuestiones jurídicas, en cambio, se dejaba aconsejar por un abogado que, por su parte, merced a sus conocimientos teóricos y experiencias prácticas desempeñaba en Ptiego un papel político independiente e influyente, aunque tampoco éste dispusiera de recursos materiales dignos de mención. El jurista le procuraba no sólo los necesarios conocimientos técnicos —en particular su habilidad para manipular los símbolos de la legalidad establecida - , sino que también le permitía participar del prestigio social de su capital simbólico como abogado ${ }^{56}$.

De un mero testaferro llegó Valverde a ser un intermediario profesional que frente a sus comitentes podia actuar con creciente independencia, y que con tal actividad se ganaba el sustento. En primer lugar, el propio Valverde, en

52 Cf. José Mariano Rodríguez de Mora, contador de Montilla, al duque, fechada en Montilla el 30 de abril de 1794 (ADMC, Contaduria de Montilla, s.i.).

53 Aunque su madre era viuda, no era tratada de «doña» (AHPCO, libro 550, Fol. 135v). En cuanto a Valverde, es tratado de «don» en los repartimientos de Paja y Utensilios de 1772, 1790 y 1799 , y sin «don» en el repartimiento de 1781 (AMP, leg. 385-2, 457-1, 531-1+2).

54 José Mariano Rodríguez de Mora, contador de Montilla, al duque, fechada en Montilla el 14 de abril de 1790 (ADMC, Contaduría de Montilla, s.i.).

55 José Mariano Rodríguez de Mora, contador de Montilla, al duque, fechada en Montilla el 12 de febreto de 1794 (ADMC, Contaduría de Montilla, s.i.).

56 José Vallesteros, mayordomo de Priego, a Joaquín de San Martín, contador de Montilla, fechada en Priego el 20 de octubre de 1783,13 de febrero de 1784 (ADNC, Contaduria de Montilla, s.i.). Cf. WINDLER, op. cit., 1992, 303-304. 
compañia de sus protectores, se esforzó por ampliar la oposición frente a la facción "duquista» ${ }^{57}$. Pero en 1788 propuso al regidor decano, como representante de esta facción, "entibiar los ánimos de diez sugetos, a cuyos impulsos él se gobernaba» ${ }^{58}$.

Si bien, formalmente, todo vecino podía presentarse como parte en el proceso pendiente y proseguir el pleito, en opinión del contador del duque en Montilla era Valverde en 1790 el único que poseía la instrucción necesaria para conseguir una sentencia favorable ${ }^{59}$. Por entonces, Valverde había llevado el pleito por la jurisdicción señorial de Priego casi hasta el extremo de su secuestro por la Corona. En la correspondencia de la administración ducal se destaca junto con sus conocimientos especialmente también su poder de convicción, frente a los notables menos experimentados en el trato con los tribunales ${ }^{60}$.

Para la financiación del pleito recibió Valverde dinero de sus comitentes, quienes esperaban poder financiar finalmente los costos de los fondos municipales de Propios ${ }^{61}$. Pero de hecho, el papel relativamente independiente de Valverde quedó puesto de manifiesto al endeudarse personalmente con la esperanza de poder ampliar su posición como intermediario. En efecto, como diputado sobreestimó entonces las posibilidades que tenía para conseguir la financiación a cargo de los fondos municipales. El endeudamiento que resultó de esta estimación equivocada ${ }^{62}$ le facilitó a la administración ducal a partir de $\mathbf{1 7 9 0}$ mover a Valverde a entrar en negociaciones, pese al estado del proceso, que por entonces le era muy propicio.

Es ante todo de interés notar cuándo y de qué modo se abrieron estas negociaciones. En 1790 la administración ducal sólo podía suspender la puesta en práctica de la sentencia de la Chancillería de Granada a favor del secuestro de la jurisdicción de Priego mediante una apelación a un tribunal superior. Además había logrado que la Chancillería mandase al corregidor de realengo de Lucena como juez comisionado a Priego para informar sobre las elecciones de diputados y personero del común, «hechas" por la Casa de Medinaceli. A la vista de su informe, el tribunal las anuló y mandó al comisario organizase otras que ganaron los «contrarios» del señor ${ }^{63}$. En esta situación extremadamente de-

57 Juan Antonio de Reyna y García, presbítero, al duque, fechada en Priego el 1 de agosto de 1785 (ADMC, Contaduría de Montilla, s.i.).

58 Duque a José Mariano Rodríguez de Mora, contador de Montilla, fechada en Madrid el 1 de enero de 1788 (ADMC, Contaduría de Montilla, s.i.).

59 José Mariano Rodríguez de Mora, contador de Montilla, al duque, fechada en Montilla el 25 de agosto de 1790 (ADMC, Contaduría de Montilla, s.i.).

60 José Mariano Rodriguez de Mora, contador de Montilla, al duque, fechada en Montilla el 7 de agosto de 1793 (ADMC, Contaduría de Montilla, s.i.).

61 José Matiano Rodríguez de Mora, contador de Montilla, al duque, fechada en Montilla el 25 de agosto de 1790 (ADMC, Contaduría de Montilla, s.i.).

62 Cf. Antonio Lozano y Valenzuela a José Mariano Rodríguez de Mora, contador de Montilla, fechada en Priego el 20 de octubre de 1794 (ADMC, Contaduría de Montilla, s.i.).

63 Dictamen de Juan Toribio Monter, abogado de Cámara del duque, fechado en Madrid, 9.2.1790; Gregorio Madrid y Garcia, regidor y fiscal de Priego, al duque, fechado en Priego, 3.2.1790 (ADMC, Contaduria de Montilla, s.i.); AHN, Consejos, leg. 1318-18, fol. 4v-6r; AMP, Actas Capitulares, 1790.

Hitquantia, LVIII/2, núm. 199 (1998) 575-605 
licada, la Casa ducal reconoció la necesidad de buscar una transacción, y de ofrecer a los notables concesiones referentes al nombramiento del cabildo. En las conversaciones con Valverde, que en primer lugar servían para elaborar la transacción extrajudicial con sus comitentes, la administración ducal pudo convencer a Valverde a colaborar en secreto con ella, prosiguiendo de tal modo los pleitos llevados en su nombre que no pudieran terminar con éxito, y finalmente a separarse por entero de ellos ${ }^{6.4}$.

Hábilmente llevó la administración ducal a Valverde a renunciar a su depósito de confianza y relaciones a cambio de unas aparentes ventajas materiales. Ya al comienzo de las negociaciones en 1790, el contador ducal estimaba que la reclamación por parte de Valverde del pago de las deudas que el pleito le había ocasionado era la única en la que estaba realmente interesado ${ }^{65}$. Como entre tanto Valverde se arrepentia de haberse retirado del pleito por la jurisdicción y los estancos, proceso que, como se ha dicho anteriormente, había llevado ya muy adelantado, y en consecuencia preparaba nuevos pasos en otro pleito por el arrendamiento de las tierras del duque, el duque, para poder mantenerlo completamente alejado de Priego y Granada, lo llamó a Sevilla en 1793 para su administración del estanco del jabón. El contador de Montilla sostenía la opinión de que, ofreciéndole a Valverde su subsistencia, se podría terminar con los pleitos por los derechos de la Casa en Priego; de otro modo, echaría probablemente a perder los esfuerzos por una transacción, y la situación se volvería peor que antes. Aunque Valverde, en opinión del contador de Montilla, no ofrecía seguridad alguna para la administración de caudales, se le dio el puesto de fiel mayor de la Fábrica de Almonas en Sevilla, que con un salario de 600 ducados anuales ( $=6.618$ reales) estaba bastante bien dotado para alguien que siempre había carecido de todo. Además le eran abonados los costos del viaje a Sevilla. Pero, transcurridos apenas unos pocos meses, Valverde dimitió de su cargo, pues no era de su agrado. El habria preferido un nombramiento como alguacil mayor de Priego. Como tal, habría ganado una influencia directa sobre la custodia del orden público en el municipio y sobre la ejecución de los decretos de los jueces. Así, habría podido entonces aportar en provecho propio todo su capital de experiencias y relaciones a un oficio que, junto con el de alcalde mayor, era especialmente importante ${ }^{66}$.

La significación que la administración ducal atribuía a las relaciones de Valverde en Priego, su lugar de origen, y en Granada, así como a su saber y expe-

64 José Mariano Rodríguez de Mora, contađor de Montilla, al duque, fechada en Montilla el 7 y el 25 de agosto de 1790; dictámenes de Juan Toribio Monter, abogado de Cámara del duque, fechado en Madrid el 10 y el 18 de noviembre de 1790 (ADMC, Contaduría de Montilla, s.i.).

65 José Mariano Rodriguez de Mora, contador de Montilla, al duque, fechada en Montilla el 25 de agosto de 1790 (ADMC, Contaduría de Montilla, s.i.).

66 José Mariano Rodziguez de Mora, contador de Montilla, al duque, fechada en Montilla el 10 y el 31 de julio, y el 7 de agosto de 1793 . El duque al contador, fechado en San Ildefonso el 19 de agosto de 1793; Gabriel Valverde Ladrón de Guevara al duque, fechado en Sevilla el 22 de enero de 1794 (ADMC, Contaduría de Montilla, s.i.). 
riencia, se evidencia en particular a partir de has medidas tomadas, a raiz de su dimisión del cargo de Sevilla, para impedir su regreso a Priego. Aunque después de haber aceptado las ofertas de la Casa de Medinaceli, Valverde ya no podía ser considerado como digno de confianza, la Casa ducal le siguió liquidando su salario como fiel. Además recibió 26.000 reales para saldar sus deudas ${ }^{67}$.

Pues ni siquiera eso bastó para impedir que Valverde regresata a Priego, lo cual habría de lamentar extraordinariamente el contador en Montilla. Si se le hubiera podido convencer de que permaneciera en Sevilla, eso le habría hecho uperder el calor de Priego y los amigos, que tiene en aquella villa adquiridos por sus travesuras $y$ enredos\%. Al final se habria visto forzado a aceptar cualquier empleo que le ofreciera la Casa ducal. En lugar de esto, Valverde quería volver a Priego, reclamar ahí de nuevo su salario como fiel, y ganar sus «intereses y buena subsistencia» a través de los medios más perjudiciales para la Casa, buscando aliados que no le fallaran ni con el nombre ni con el dinero. El se mantendría a la sombra, influyendo y conduciendo a los otros, aportándoles sus conocimientos e incluso documentos, pues desde hacía años no había ejercido otro oficio más que reunir papeles. Su casa se asemejaba entre tanto a un "rarcbivo general). Si ya no recibía sueldo alguno de la Casa ducal, habría de buscarse otros medios para vivir: "(...) y cuando sabe que por muchos años lo consiguió baciendo el papel de agente de revoltosos, no será estraño procure emprender de nuevo oficio gue tiene conocidos ${ }^{68}$. Justamente para impedir esto, el contador proponía designar a Valverde para un empleo de la Casa ducal en Castilla, Aragón, Cataluña o Valencia, es decir, lo más lejos posible de su pueblo de origen. Sin embargo sabía que a esto se oponía la intención de Valverde de regresar a Granada o a Priego, donde había recopilado muchos documentos y podía inducir a ottos a pleitear ${ }^{69}$.

Aunque Valverde regresó a Priego, los esfuerzos de la administración ducal no fueton estériles. Lo habían inducido a un comportamiento que destruía todo su capital de prestigio, fundamento de su influencia. Valverde había además acentuado este perjuicio, exponiendo a un presbítero tras su retorno a Priego las ventajas de una transacción con la Casa ducal. Con ello sólo había conseguido el resultado inverso: la postura de los contrarios se había endurecido aún más a causa de la impresión de que el duque los temía. Pero con satisfacción habría de comprobar la administración ducal que Valverde se había convertido en realidad en objeto de mofa, y que en Priego ya no le quedaban ni amigos ni partido ${ }^{70}$.

67 Dictamen de Juan Toribio Monter, abogado de Cámara, fechado en Madrid, el 13 de marzo de 1794; José Mariano Rodríguez de Mora, contador de Montilla, al duque, fechada en Montilla el 30 de abril de 1794 (ADMC, Contaduria de Montilla, s.i.).

68 José Mariano Rodríguez de Mora, contador de Montilla, al duque, fechada en Montilla el 12 de febrero de 1794 (ADMC, Contaduría de Montilla, s.i.)

69 José Mariano Rodríguez de Mora, contador de Montilla, al duque, fechada en Montilla el 30 de abril y el 31 de mayo de 1794 (ADMC, Contaduría de Montilla, s.i.).

70 José Mariano Rodríguez de Mora, contador de Montilla, al duque, fechada en Montilla el 30 de septiembre de 1794 (ADMC, Contaduria de Montilla, s.i.).

Hispania, LVIIl/2, núm. 199 (1998) 575-605 
Que todavía no se estaba muy seguro del asunto, lo pone de manifiesto el hecho de que a Valverde le fueran abonados los gastos del viaje de regreso, así como que todavía le fuera liquidado el salario que disfrutaba en la administración del estanco del jabón en Sevilla ${ }^{71}$. Sin embargo, consintiendo a las propuestas de la Casa de Medinaceli, había de algún modo vendido su caudal de confranza y relaciones. Como no estaba a la altura de sus nuevas tareas en la administración del estanco del jabón de la Casa ducal, no podía convertir este capital suyo en una posición institucionalizada, ni aprovechar las posibilidades que en principio se vio la Casa obligada a ofrecerle en su administración.

Es interesante que, en su calidad de intermediario al servicio de los contrarios de la Casa ducal, fuera Valverde reemplazado inmediatamente por otro boticario que desde 1790 había ido ocupando progresivamente un primer plano ${ }^{72}$. Manifiestamente, la demanda de los servicios de intermediarios se había mantenido.

\section{MEidIACIÓN, CULTURA JURÍDICA Y PRACTICA JUDICIAY}

La trayectoria de Gabriel Valverde aporta algunos elementos importantes para la comprehensión de la funcionalidad del saber jurídico en las tedes sociales. Más allá de los juristas con formación universitaria, este análisis tiene que atender también a unos intermediarios con orientación práctica. Aunque el propio Valverde fracase al final, queda el hecho llamativo de que inmediatamente fuera reemplazado por otro agente que se había ido perfilando gradualmente junto a él, y que no habría de deparar menos preocupaciones a la administración ducal.

En un estudio sobre los Vázquez, una familia sevillana de labradores, Héran ya ha destacado como esta familia procuraba que alguno de sus hijos adquiriera el saber jurídico necesario para reducir su dependencia respecto de especialistas externos. La formación jurídica otorgaba prestigio social y una mayor eficiencia en lo político, así como ventajas en la administración de bienes y en la planificación de las estrategias de herencia ${ }^{73}$. De igual modo, las investigaciones acerca del caciquismo de la Restauración apuntan a la significación de los juristas como intermediarios entre los municipios y el ámbito nacional. Entre los diputados de Cortes y los senadores se encontraban numerosos políticos cuya posición se basaba más bien en una formación y experiencia jurídicas que en recursos materiales ${ }^{74}$.

71 José Mariano Rodriguez de Mora, contador de Montilla, al duque, fechada en Montilla el 10 de septiembre y el 12 de noviembre de 1794; duque al contador, fechado en San Ildefónso, el 27 de septiembre de 1794 (ADMC, Contaduría de Montilla, s.i.).

72 Cf. WINDLER, op. cit., 1992, 301-302.

73 HÉrAN, François, Le bourgeois de Séville. Terre et parenté en Andalousie, París 1990.

74 Véase YANINI MONTES, Alicia, «Parlamentarios valencianos: los diputados (18761901)", Cabiers de l'Université de Pau et de pays de lAdour, núm. 1 (1983), 83-97, aqui 84-87; CARASA So'ro, Pedro/Martin de la Guardin, Ricardo M./PÉrez López, Pablo/PÉrez Sánchez, 
Desde una posición mucha más modesta, la trayectoria de Valverde se relaciona con el desarrollo de una cultura jurídica más profesionalizada que acentuaba en el siglo XVII la dependencia de los legos respecto de los abogados ${ }^{75}$. Los procedimientos y las formas de interacción cada vez más especificas de los abogados y del mundo judicial propiciaron el ascenso de intermediarios especializados. La creciente importancia social de los tribunales reales y las administraciones, así como de la abogacía y la centralización formal de las competencias resolutorias, intensificaban, más allá del ámbito del cual se ocupa de ordinario la investigación sobre la profesionalización jurídica, unos procesos de diferenciación social que posibilitaban a hombres de condiciones materiales modestas ganar influencia en dependencia de familias de notables. Conforme a lo largo del siglo XVII se iba intensificando la interacción entre los municipios y los agentes de poderes externos, y cuanto más la política local se orientaba a estos últimos, tanto más necesarios se hicieron especialistas como Valverde, que mediaban entre las comunidades y los tribunales reales sin disponer siempre de una posición formal como procuradores o agentes de pleitos. La demanda de un saber jurídico se vinculaba con la necesidad de disponer de múltiples redes informales de telaciones, así como de conocimientos acerca de la práctica de los tribunales que, si bien se refería a notmas escritas, era codeterminada esencialmente por lealtades personales. Factores materiales, como las deficiencias de los caminos, contribuyeron a fomentar tal demanda.

Tal como A. M. Hespanha ha observado también en el caso de la justicia real en Portugal, el desplazamiento de las situaciones de conflicto hacia un discurso formalizado y diferenciado de los usos jurídicos locales, provocó unos efectos de diferenciación social. Justamente a causa del carácter específico del campo jurídico, los conocimientos de las normas jurídicas vigentes, de su interpretación o del modo de trabajo de los tribunales, pasaron a ser factores de estructuración social ${ }^{7}$. La cultura jurídica como un «conjunto de instrumentos

Guillermo A., «Castilla en las Cortes de la Restautación. Poder politico y dominio social de la oligarquia vallisoletana, 1876-1903m, en: Las Cortes de Castilla y León, 1188-1988. Actas de la tercera etapa del Congreso cientifico sobre la Historia de las Cortes de Castilla y León, León, del 26 al 30 de septiembre de 1988, vol. 2, Valladolid 1990, 457-477; Díez Cano, Leopoldo-Santiago, «Representación parlamentaria y poder económico en la Restauración: el caso salmantinon, en: Las Cortes de Castilla $y$ Lón (misma nota), 479-491; MERINß̨o MARTíN, María Jesús/SÁNClIEZ MARROYO, Fernando, «El monopolio del poder en la Extremadura contemporínea», Espacio, Tiempo y Forma, serie 5 , vol. 3 (1990), 101-117, aquí: 108-117.

75 KAGAN, op. cit., 1981, 241-246. Cf. acerca de Inglaterra: PJJSS; op. cit., 1986; en cuanto a Francia: KARPIK, op. cit., 1995, 59-150. Cf. RANIERI, Filippo, "Vom Stand zum Beruf. Die Professionalisierung des Juristenstandes als Forschungsaufgabe der europäischen Rechtsgeschichte der Neuzeibs, Ius Commune, 13 (1985), 83-105; idem, "Die Juristen im Alten Reich des 17. und 18. Jahrlhunderts. Ein Forschungsprojekbo, en: Georg SCIMIDT (ed.), Stände und Gesellschaft im Alten Reich, Stuttgart, 1989 (Veröffentlichungen des Instituts für Europäische Geschichte Mainz, Abteilung Universalgesclich te. Beihefte, 29), 231-244.

76 Véase A. M. HESPANHIA, op, cit, 1993a, 411-435. Cf. idem, sabios y rústicos. La dulce violencia de la razón jurídica», en: idem, op. cit., 1993b, 17-60.

Hipania, LVIII/2, núm 199 (1998) 575-605 
cognitivos» que permiten unas «relaciones comunicativas especificas» no es socialmente neutral, sino que acarrea conflictos en una forma tal que provoca a su vez diferenciaciones sociales y vuelve necesaria la intervención de intermediarios especializados ${ }^{77}$.

En primer lugar, hay que pensar en el hecho elemental de que todos los pasos de un proceso, desde la demanda hasta la sentencia del juez, se fijaban por escrito ${ }^{78}$, y de este modo se sustraían al acceso inmediato de amplios círculos de población no alfabetizados. Sin entrar más detenidamente en las preguntas que se plantean en conexión con esto, sea dicho que no queda duda alguna de que la alfabetización en España durante los siglos XVIII y XIX era escasa en comparación con otros países europeos ${ }^{79}$, y que, por consiguiente, la importancia de lo escrito había de provocar efectos de diferenciación especialmente pronunciados ${ }^{80}$.

Si se rastrean los efectos sociales de la difusión creciente de lo jurídico, es importante prestar atención a la práctica judicial ${ }^{81}$. A través de procedimientos que en principio debían poner coto a la arbitrariedad de los jueces, se anticipaton, por debajo del nivel judicial, decisiones importantes. Quien acudía a un tribunal tenía que usar buena parte de sus esfuerzos en estos procedimientos y en las relaciones sociales tensadas en torno a ellos. No bastaba con cumplir meramente los requisitos formales, sino que había que instrumentalizarlos de un modo eficiente con miras a los objetivos procesales. Los procedimientos de los tribunales reales, cuyos desarrollos hasta 1700 ha investigado Kagan, no parecen haber cambiado sustancialmente en el siglo XVIII ${ }^{82}$. En cambio, con la influencia de los tribunales reales y la abogacía creció el alcance social de una actividad formalizada jurídicamente. Ocasiones decisivas para influir en un proceso se abrian ya con un detalle, en apariencia tan banal, como la fijación de la fecha del juicio por el repartidor. Con vistas a la manipulación del desarrollo de un pleito, se solian comentar las posibilidades que ofrecían unas buenas re-

77 SCHOLZ, Johannes-Michael, «Kommunikative Kompetenz und soziale Verteilung. Juristische Medienpolitik im spanischen 19. Jahrhundert», Ius Commune, 19 (1990), 137-186, aquí en particular: $138,140-141$.

$78 \mathrm{KAGAN}$, op, cit., $1981,37$.

79 Varios autores, De lalphabétisation aux circuits du livre en Espagne, XVTe-XIXe siècles, París, 1987.

80 Entre mediados del siglo XVIn y mediados del XIX la creciente alfabetización no parece haber estado acompañada de una difusión correspondientemente mayor del saber transmitido por escrito: un estudio sobre Lorca, una agrociudad de la provincia de Murcia, muestra, por un lado, una disminución en conjunto de las existencias de libros, y, por otro lado, una creciente diferenciación social - un crecimiento de las grandes bibliotecas de las oligarquias locales a expensas de las pequeñas (MORENO MAR'IINEZ, Pedro Luis, Afabetización y autura impresa en Lorca (1760-1860), Murcia, 1989. Cf. Scholz, op. cit., 1990, sobre todo 140).

81 CF. SCHOLZ, op. cit., $1992 \mathrm{~b}, 303-312$.

82 Investigaciones posteriores tendrian que precisar esta tesis, que se apoya en la coincidencia entre los análisis de Kagan y los procedimientos que aparecen en la correspondencia de la Casa de Medinaceli. 
laciones con los relatores. Las partes podían alargar un proceso reclamando la declaración de testigos del Nuevo Mundo, o la realización de determinadas vistas de ojos, rechazando como parciales a jueces y a telatores, o apelando contra resoluciones a varios tribunales diferentes ${ }^{83}$.

A menudo resulta difícil seguir en concreto el sentido de las decisiones procesales. Especialmente informativa a este respecto es la correspondencia privada de las partes ${ }^{84}$. Si se toma en serio la relevancia de los procedimientos que preceden a las sentencias, se descubren dimensiones esenciales de la significación de las instancias locales. Incluso en aquellos ámbitos en los que las competencias de la jurisdicción ordinaria no se veían limitadas por fueros de estamentos, gremios o corporaciones territoriales, queda puesta en cuestión la imagen simple de un centralismo monárquico. Procesos ante las Audiencias, Chancillerías o Consejos en Madrid, que aparentemente documentan la competencia de los jueces reales, resultan en aspectos esenciales sólo comprensibles en sus dimensiones locales. Así, una regalía monárquica por excelencia como es la concesión y confirmación de hidalguías, dependía de modo decisivo de la capacidad de los afectados para influir, merced a su poder y su prestigio en los municipios, en la recopilación de pruebas, como por ejemplo conseguirían los Alcalá Zamora a principios del siglo XIX ${ }^{85}$.

Ante los tribunales, las mejores posibilidades las tenían aquellos pleiteantes que tuvieran a su disposición, redes de relaciones que les permitieran intervenir en las diferentes fases del proceso. Sin duda, eran las grandes casas nobiliarias las mejor organizadas y, por consiguiente, las más presentes. En los tribunales importantes para la conservación de sus derechos, disponían de equipos de abogados, procuradores y agentes de negocios, conocedores de la jurisprudencia, del derecho procesal y, sobte todo, de los usos y prácticas del mundo judicial. Los abogados eran principalmente expertos en Derecho, mientras que los procuradores y agentes de negocios lo eran en las prácticas procesales ${ }^{86}$.

Las instrucciones mediante las cuales la Casa de Medinaceli regulaba la actividad de sus Contadurías en Sevilla, Barcelona y Valencia, también se expresaban acerca de la actividad de los agentes de negocios, procuradores y abogados del duque. Los agentes de negocios, por indicación de las Contadurías y en común acuerdo con los abogados de la Casa, debían seguir el cumplimiento de los trámites procesales por parte de los escribanos, relatores, etc., pero, sobre todo, cuidar las redes de relaciones con los tribunales y, no en últi-

\footnotetext{
83 KAGAN, op. cit., 1981, 39-41, 45-48.

84 No sólo la aristocracia, sino también muchos municipios encomendaban a agentes la custodia de sus intereses ante los tribunales. R. L. KAGAN (op. cit., 1981) ha consultado con provecho las correspondencias que se guardan en el Archivo Municipal de Toledo.

85 Cf. KAGAN, op. cit., 1981, 120-121; WINDLER, op. cit., 1992, 82-87, 104.

86 KAGAN, op. ait., 1981, 52. Acerca de los procuradores: 57-60. Los procuradores del número de los tribunales no necesitaban haber terminado sus estudios, pero en cambio eran examinados en cuanto a sus conocimientos jurídicos antes de que pudieran recibir tal oficio (comprable). Acerca de los abogados: 60-77.
}

Hípanza, LVIII/2, núm. 199 (1998) 575-605 
mo término, con el personal subalterno, en apariencia tan poco significativo. El agente de negocios, o dado el caso el contador o su asesor, debían visitar al juez tan a menudo como fuera preciso para conseguir un juicio favorable. La Casa pretendía establecer una relación duradera de confianza personal que luego resultara decisiva durante los pleitos. Por eso, el reglamento de la Contaduría en Barcelona indicaba expresamente a los agentes de negocios que tenían que visitar a los jueces «en sus propias casas». El reglamento y la correspondencia ponen de manifiesto que estas relaciones, que contradicen la imagen de una actividad judicial escindida del ámbito privado, constituían una parte evidente dentro de la praxis de los tribunales. El reglamento de Barcelona prescribia a los agentes lo siguiente: "Y conseguido esto [es decir, la sentencia] dará noticia a mi asesor general y Contaduria, y prevendrá si considerase preciso se haga alguna demostración de gratitud con el relator, $u$ otra persona, que aya facilitado el despacho, para que de común acuerdo se resuelva y ejecute lo conv [enien]tes) ${ }^{87}$. Tales disposiciones confirman asimismo, y no en último término, la significación atribuida a la influencia del personal no judicial, y en especial medida de los relatores, sobre el desarrollo de un proceso.

Como casi ningún otro, los agentes de negocios asalariados de las grandes casas nobiliarias habian hecho de la mediación de relaciones su profesión. Las casas nobiliarias esperaban de ellos profundos conocimientos acerca de los modos de funcionamiento de los tribunales, tacto y don de gentes, así como discreción y fidelidad absoluta ${ }^{\text {s8 }}$. Junto con esto, también la Casa ducal ponía en juego las relaciones personales de sus empleados para influir en los tribunales. A propuesta propia viajó en 1783 a Granada el alcalde mayor de Priego para "prepatat» con sus informaciones a los oidores de la Chancillería, de los cuales siete formaban parte de sus amigos, unos por paisanos, y los otros, por haber sido compañetos de estudios ${ }^{89}$.

A diferencia de la Casa de Medinaceli, los notables de Priego no disponían en Granada de una infraestructura personal permanente. A falta de apoyos familiares en el tribunal, se véan obligados a recurrir a los servicios de intermediarios menos comprometidos y menos fiables. Que esta solución, y justamente en litigio con una casa nobiliaria, quedaba afectada de penosos inconvenientes, lo pone de manifiesto, junto con muchos otros, el ejemplo de Priego.

87 Instrucción para la Contaduría mayor de los Estados Ducado de Cardona y Marquesado de Aytona y sus agregados, que reside en la ciudad de Barcelona, y demás ministros y oficiales que sirven en dichos Estados, fechada en Madrid el 20 de noviembre de 1745, cap. 31 a 33, fols. 70r-81r (cita literal: 77v) (ADMC, Archivo Histórico, leg. 240-13).- Copia de la instrucción dada a la Contaduría de los Estados de Alcalá que reside en Sevilla, fechado en Madrid el 6 de octubre de 1744, cap. 28, 29, fols. 65r-68v (ADMC, Manuscritos, libro A/18).- Instrucción para el gobierno de los Estados de Segorbe y Denia en Valencia, fechado en San Lorenzo el 16 de noviembre de 1764, cap. 60 a 67 (ADMC, Archivo Histórico, leg. 190-3).

88 CE. WINDLER, op. cit., 1992, 442-444.

89 Joaquin de San Martín, contador de Montilla, al duque, Montilla, 14 de octubre de 1783; Julián Romero, alcalde mayor de Priego, al contador, Priego, 7 de noviembre de 1783 (ADMC, Contaduría de Montilla, s.i.). 


\section{MEDIACIÓN E INTEGRACIÓN POLÍTICA}

A primera vista, puede surgir la impresión de que el intermediario Valverde instrumentalizaba las normas jurídicas asi como las posibilidades ofrecidas $\mathrm{cn}$ los tribunales reales, para conseguir fines que obedecían a una legitimidad que se correspondía con las circunstancias en Priego, divergente de la legalidad de la Monarquía. En la práctica, sin embargo, la Corona dependía tanto como los notables de Priego o la Casa de Medinaceli de la movilización de redes informales. En la España de finales del Antiguo Régimen, las instituciones eran sólo una especie de armazón que daba consistencia a los lazos personales que vinculaban poderes plurales y policéntricos. La demanda de los servicios de intermediarios especializados provenía entonces tanto desde abajo como desde arriba. Valverde, por un lado, prestaba importantes servicios a los notables de Priego en sus litigios con la Casa ducal, y por otro lado, facilitando a los tribunales reales la intervención en estos conflictos, ayudaba a que su patronazgo se hiciera efectivo.

También dentro de las administraciones y los tribunales reales competian lealtades personales con el Derecho formal de la Monarquía ${ }^{00}$. Redes clientelares, que canalizaban servicios materiales e inmateriales recíprocos, poseían en la España del siglo XVIII su propia legitimidad, que, según las circunstancias respectivas, ponía abierta o latentemente en cuestión el orden legal. Lo que para un pensamiento determinado por valores estatales aparece como corrupción, se analiza más adecuadamente como una interacción conflictiva entre sistemas de valoración diferentes.

La centralización como imposición y sometimiento unilateral de la periferia por parte de un Estado dominante existió sobre todo en la cabeza de tratadistas y oficiales reales. En la práctica, se trataba de procesos sociales acunados por relaciones recíprocas entre las diversas instancias ${ }^{91}$. El fortalecimiento de la autotidad de los tribunales reales a lo largo del siglo XVIII acentuó la disposición a resolver los conflictos ante tales instancias y a buscar, frente a las administraciones señoriales, la protección de la Corona. En el caso que nos ocupa, la disposición por parte de los litigantes a negociar una transacción, muestra de qué modo los notables de las agrociudades andaluzas se servían del recurso a la Chancillería. Al investigar los pleitos en la España del Antiguo Régimen, se advierte su larga duración, así como el hecho de que a menudo no llegaran a resolverse. Así, Kagan ha señalado que durante los siglos XVI y XVII poco más del $6 \%$ de los procesos incoados ante la Chancillería de Granada habrian de terminar en una sentencia formal ${ }^{\text {g2 }}$. Las constataciones de que la justicia era lenta, y que sobre todo los demandantes necesitados tenían dificultades para llevar los pleitos hasta conseguir una sentencia, no son desacertadas. Pero en muchos casos faltaba la intención firme de tesolver los con-

90 Cf. Hespanl LA, «La economia de la gracia», en: idem, op. cit., 1993b, 151-176.

91 Acerca de la región de Murcia, cf.: Pérez Picazo/Lemeunier, op. cit., 1988, 333-335.

22 KAGAN, op, cit., 1981, 84.

Hiopania, LVIII/2, nüm 199 (1998) 575-605 
flictos ante el tribunal. En un sistema de poder basado en lealtades personales, las demandas judiciales servían como medidas de presión. Se apelaba al patronazgo de un tribunal para mejorar la propia posición dentro de transacciones extrajudiciales ${ }^{93}$. Por lo tanto, los procesos judiciales de ningún modo excluían las transacciones, sino que, a menudo, la apelación a un tribunal no era más que un aspecto de un largo conflicto ${ }^{34}$. Según las circunstancias, podia parecer oportuno encauzar los conflictos - en el caso que nos ocupa, con el señorpor vías judiciales. Las partes se referían a la jurisprudencia y a las normas legales que, sin embargo, interpretaban a su modo. Estudiar la justicia unilateralmente como un instrumento de disciplinamiento, implica perder de vista el hecho de que acusadores y acusados recurrían a ella como parte de estrategias siempre nuevas y condicionadas por las circunstancias ${ }^{35}$. Dentro de este campo de interpretación, jugó Valverde como intermediario un papel central.

En nuestro caso, este encauzamiento de conflictos por vias judiciales puede observarse no sólo desde el lado de Valverde. También sus adversarios procedieron de modo similat, tal como puede seguirse ejemplarmente en las disputas por la prórroga del mandato de diputado de Valverde. En principio, éste había sido elegido para los años 1783 y 1784. Para fortalecer la facción que buscaba el patronazgo de los tribunales reales frente a la administración señorial y el cabildo nombrado por ésta, el Consejo de Castilla prolongó por dos veces el tiempo de ejercicio del cargo de Valverde como diputado. Esta medida le pareció oportuna al fiscal del Consejo de Castilla, en vistas al papel del diputado en el fortalecimiento del poder de la Corona $\%$

Los adversarios de Valverde -el cabildo puesto por el duque de Medinaceli, de común acuerdo y con el apoyo de la Contaduría-, trataron de conseguir la revocación de dicha prolongación alegando los perjuicios que aquel ocasionaba como boticario y como diputado. Según ellos, Valverde, con el descuido de la botica debido a sus frecuentes ausencias, tepresentaba una amenaza para la salud pública. En la correspondencia de la Contaduría ducal puede seguirse el modo como el conflicto con el diputado y boticario Valverde fue vertido en argumentos jurídicos inspirados por la imagen de una medicina profesionalizada. Desdeñando las leyes del Reino y sin escrúpulos, a la vista del perjuicio para

93 Hasta ahora, la significación de tales transacciones en la España del Antiguo Régimen apenas se ha investigado: acerca de la región de Murcia, cf. PÉREZ PICAZO/LEMBUUNILR, op. cit, $1988,325-327$; cf. MARTONE, Luciano, Arbiter-Arbitrator. Forme di giustizia privata nell'età del diritlo comune, Napoli, 1984 (=Storia e diritto. Studi, 13).

94 Acerca de la relación entre la demanda ante el tribunal y la transacción extrajudicial: CASEY, James, «Household disputes and the Law in early-modern Andalusia», en: BOSSY, John, ed., Disputes and Settlements. Lav and Human Relations un the West, Cambridge (etc.), 1983, 189-217, sobre todo 211-212.

95 Desde la perspectiva de la investigación sobre la criminalidad, los artículos en: BI.AUIR'I, Andreas/SCINWLRHIOFI;, Gerd, ed,, Mit den Waffen der Justiz. Zur Kriminalitatsgeschichte des späten Mittelalters und der früben Neuzeit, Francfort del Meno, 1993.

96 AHN, Consejos, leg. 897-11, Fol. 1r-3r, 38r-40r, 42r, 43r. 
muchas vidas humanas y de las quejas de los médicos, Valverde habría derivado la elaboración y venta de medicamentos a su mujer o a sus aprendices, desoyendo incluso las amonestaciones de la última visita, a saber del representante de la Corona. Además de los reproches por las frecuentes ausencias del boticario Valverde, se reactivó un viejo expediente en el que se le había inculpado por la ejecución incorrecta de la receta de un médico y la difamación de éste ${ }^{97}$.

Así, el cabildo de Priego consiguió una sanción contra Valverde por parte del Tribunal del Real Protomedicato, competente para la inspección de las actividades médicas. Para ello resultaron decisivas las redes de relaciones de la Casa de Medinaceli, cuya Contaduría había inspirado y dirigido el pleito. Cuando el Real Protomedicato había pronunciado su sentencia, el duque envió el despacho a su contador en Montilla, quien a su vez debía transmititlo con total discreción al alcalde mayor de Priego. Las medidas no debían ser tomadas ex officio por el alcalde mayor, sino salir del cabildo para que no se pudiera reprochar al juez el haber actuado por «despique» u odio. El alcalde mayor movió al regidor encargado del seguimiento de los pleitos para que le solicitara el cumplimiento del despacho ${ }^{88}$.

Tal como el alcalde mayor se había temido, el Consejo de Castilla se limitó sin embargo a consignarle al intendente de Córdoba que se preocupara de que, durante sus ausencias, Valverde encargara la gestión de su botica a una persona capacitada, y en cambio rechazó el recurso interpuesto contra la prolongación del mandato de diputado. El efecto de la decisión dependía por tanto de la postura que adoptara el intendente: el diputado Valverde siguió conservando un amplio campo de acción, pues tan solo con la transferencia temporal de la botica a otro boticario aprobado, podía él tesponder a las exigencias que se le imponían ${ }^{g 9}$. Pero a comienzos de los años noventa los adversarios de Valverde lograron por fin que el Tribunal del Real Protomedicato cerrara su botica y le condenara a una multa de 50 ducados, alegando que no se había ocupado en absoluto de la botica, sino que, en vez de ello, la había dejado en manos de un empleado sin título, así como tampoco había ofrecido los medicamentos necesarios 100

97 El duque a Joaquín de San Martín, contador de Montilla, fechada en Aranjuez el 23 de junio de 1785; Antonio Serrano Ortega, alcalde mayor, al duque, fechada en Priego el 8 de agosto de 1785 (ADMC, Contaduria de Montilla, s.i.); cabildo 12 de julio de 1785 (AHN, Consejos, leg. 897-11, Fol. 4v-5r).

98 El duque a Joaquín de San Martín, contador de Montilla, fechada en San Lorenzo el 7 de noviembre de 1785; contador a Antonio Serrano y Ortega, alcalde mayor, fechado en Montilla el 12 de noviembre de 1785; alcalde mayor al contador, fechado en Priego el 18 de noviembre de 1785 (ADMC, Contaduria de Montilla, s.i.).

99 Francisco Pozuelo al duque, Madrid, 16 de enero de 1786; duque a Joaquín de San Martín, contador de Montilla, fechada en El Pardo el 21 de enero de 1786; contador al duque, fechada en Montilla el 1 de febreto de 1786 (ADMC, Contaduria de Montilla, s.i.); AHN, Consejos, leg. 897-11, Fol. 35r.

100 José Mariano Rodríguez de Mora, contador de Montilla, al duque, fechada en Montilla ef 30 de abril de 1794 (ADMC, Contaduria de Montilla, s.i.).

Hispania, LVIII/2, núm. 199 (199B) 575-605 
Este caso muestra cómo los adversarios del intermediario instrumentalizaban a su vez las normas legales y vertían el conflicto en argumentos jurídicos que nada tenían que ver con el verdadero asunto de litigio. La Contaduría ducal, especialmente capacitada para ello gracias a su presencia en el municipio y en la Corte, traducía el conflicto al lenguaje de la burocracia reformista. Los criterios profesionales de elaboración de los medicamentos y ejecución de las recetas de los médicos, de los cuales el cabildo de Priego y la Contaduría ducal esperaban que fueran los mismos que los de los jueces en la Corte, no se cotrespondían en absoluto con las limitadas exigencias a la profesionalidad de los boticarios en Priego de Córdoba. En 1790, el mismo contador de Montilla concedió, en una consulta reservada al duque, que el funcionamiento de la botica jamás había dado en Priego auténticos motivos de queja ${ }^{101}$.

\section{MEDIANDO RELACIONES: EL ASCENSO DE LA FAMILIA ALCALÃ ZAMORA}

La mediación de relaciones entre tribunales y legos ofrecía a especialistas cualificados de condiciones materiales modestas una posibilidad de mejorat su situación social. Queda por dilucidar la cuestión de por qué en Priego, al cabo de un tiempo, algunos de los comitentes llegaran a hacerse con el campo de acción que en un principio habían ocupado Valverde y otros intermediarios.

La demanda de un saber especializado, fomentada por la crecida importancia de la administración y los tribunales reales y la tendencia a verter los conflictos sociales en cauces judiciales, pudo ser satisfecha de diversas maneras. En el caso de Priego, los notables influyentes a nivel local, pero carentes de apoyos familiares poderosos en los tribunales superiores, recurrieron en un primer tiempo a los servicios de intermediatios especializados. Este comportamiento, que igualmente se puede observar en otros municipios, todavía no exigía una adaptación profunda de las estrategias familiares de relaciones, tal como, en el caso de los Alcalá Zamora, llegará a suceder a partir de la siguiente generación.

Un Valverde Ladrón de Guevara es presentado unánimemente como un "luchador solitario", que, sin el apoyo de una red diversificada de parientes, amigos y clientes, actuaba en dependencia de sus comitentes. En el caso de Valverde, la cotrespondencia de la administración ducal no hace alusión a una red familiar que le hubiera sostenido, ni en Priego ni en Granada. Su interés por los pleitos se explica a partir de la posición que mantenía en estos, y no a partir del asunto de litigio, que le atañía en bien poco o en nada. Además, en cuestiones de Derecho tenía que hacerse aconsejar por un abogado, pues si bien conocía las prácticas sociales de los tribunales, en cambio él mismo no era letrado. Con ello se vinculaba también su incapacidad de asegurar institucionalmente una posición sostenida sobre redes informales. Fatal le resultó aceptar los ofrecimientos de la administración ducal, que trabajaba con gran habilidad para com-

101 José Mariano Rodriguez de Mora, contador de Montilla, al duque, fechada en Montiłla el 14 de abril de 1790 (ADMC, Contaduria de Montilla, s.i.).

Hipania, LVII/ /2, núm. 199 (1998) 575-605 
prometerle a los ojos de sus comitentes, y para destruir de este modo el capital inmaterial de relaciones sobre el que se sostenía su influencia.

Los Alcalá Zamora tenían un interés propio en el asunto del pleito y, por lo tanto, podían seguir ampliando, merced a triunfos en los pleitos, una posición social ya previamente alcanzada. Si bien a finales del siglo XVIII los Alcalá Zamora no contaban entre las familias más ricas de Priego, gozaban en cambio de un sólido bienestar que supieron además incrementar gradualmente. Los Alcalá Zamora eran una familia de parvenus, que sólo a comienzos del siglo XIX logró obtener de la Sala de Hijosdalgo de la Chancillería de Granada el reconocimiento de una dudosa hidalguia notoria. Tal como se ha dicho al principio, durante los años ochenta y noventa tomaron parte en los pleitos dos hermanos Alcalá Zamora, don Francisco Ubaldo y don José Pío. Francisco Ubaldo, maestro tejedor de tafetán, y su padre, mercader de seda, tenían que contentarse con el tratamiento de "don», mientras que su suegro, "labrador por su mano», figuraba en el catastro de Ensenada incluso sin este tratamiento honorífico ${ }^{102}$. Cuando se hizo el catastro, los bienes inmuebles de los Alcalá Zamora en Priego atestiguaban una situación económica decente, sin más, con un producto anual de 9.075 reales ${ }^{103}$. Los repartimientos de la contribución de Paja y Utensilios indican cierto ascenso económico; así en 1807, uno de los hijos de Francisco Ubaldo, Pedro, figuraba entre los contribuyentes seculares varones en el décimo lugar ${ }^{104}$.

Dentro del municipio, los Alcalá Zamora se apoyaban en una red de relaciones familiares mucho más diversificada que la de Valverde Ladrón de Guevara. Durante los años 1780 y 1790 , en el momento álgido de los pleitos con la Casa ducal, el presbítero don José Pío Alcalá Zamora estaba estrechamente vinculado con otros dos presbíteros que en 1790 estaban considerados como las personas más poderosas de Priego y los cabecillas de los contrarios de la Casa de Medinaceli. Como el abad de la vecina localidad de Alcalá la Real nombraba el clero de la parroquia de Priego sin participación de la Casa ducal ${ }^{105}$, tales amistades trabaron redes de relaciones fuera del dominio señorial, las cuales ampliaron el campo de acción de los Alcalá Zamora. El fuero eclesiástico prohibía al alcalde mayor señorial la intervención sobre las personas o los bienes de los presbíteros.

Un cietto bienestar económico y sus redes de relaciones pusieron a los $\mathrm{Al}$ calá Zamora en situación de ir ampliando gradualmente su poder político. A partir de la biografía de los hijos de don Francisco Ubaldo, se puede concluir que éste trató de poner a sus hijos en situación de ocupar una posición que trascendiera los límites de su pueblo y de ganar influencia bajo unas condiciones políticas cambiantes. Ya el modo como escogió a los padrinos de bautismo

\footnotetext{
102 AHCPO, lib. 550, f. 65r, 172v.

103 AHCPO, lib. 545, f. 440v-459r.

104 AMP, lib. 385-2.

105 Joaquín de San Martín, contador de Montilla, al duque, fechada en Montilla el 26 de marzo de 1782 (ADMC, Contaduría de Montilla, s.i.).

Hispania, LVIII/2, núm. 199 (1998) 575-605
} 
de su hijo don Pedro dan testimonio de la voluntad de emplazar al recién nacido dentro de una red lo más diversificada posible de relaciones sociales, enlazada tanto con la administración señorial como con la Iglesia. Junto con el ya citado tio, el presbítero don José Pío Alcalá Zamora, se encontraban el alcalde mayor de Priego y el vicario de la parroquia. Don Pedro, secretario del general de la quinta división del ejército del centro en la guerra de la Independencia, capitán de caballería retirado en 1816, fue como su padre, don Francisco Ubaldo, familiar y, a partir de 1818, alguacil mayor del Santo Oficio de la Inquisición. También en 1818 fue nombrado regidor de Priego. El mismo don Pedro, que con semejantes títulos documentaba su eficaz emplazamiento dentro de las redes de relaciones del Antiguo Régimen, supo también ajustatse a las nuevas condiciones institucionales de la monarquía constitucional - como diputado provincial de Córdoba en el Trienio liberal y como diputado a Cortes y jefe político de Sevilla tras la muerte de Fernando VII-. Por su parte, su hermano don José Julián Alcalá Zamora abrió como doctor en Derecho una tradición familiar que habrá de atribuir gran importancia a la adquisición de una formación jurídica. Los conocimientos de las normas legales y de su práctica, así como la capacidad de controlar una red de relaciones muy extendida, fueron tan decisivos para el ascenso de la familia Alcalá Zamora como sus recursos económicos ${ }^{106}$.

Estas circunstancias fueron características para muchas familias influyentes en las agrociudades del sur de España, contrariamente a las premisas de una historiografía empeñada en el análisis economicista de clases sociales. Una investigación sobre las condiciones materiales de las élites políticas en agtociudades de la baja Andalucía a finales del Antiguo Régimen, conduce a matizar la imagen de una sociedad andaluza latifundista estructurada en gran parte con arreglo a criterios de propiedad. Si bien las familias dominantes disponían por lo general de una posición dentro de las relaciones de producción que las ponía en situación de ofrecer subsistencia material a un buen número de clientes, en cambio, no se puede hablar de una correlación entre recursos económicos y poder político ${ }^{107}$.

Protegidos por los tribunales reales y los intendentes - como intermediarios más burocratizados e inmediatamente dependientes de la Cotona-y ayudados en su vertebración política local por reformas como la introducción de diputados y personeros del común por el Consejo de Castilla, los Alcalá Zamora y otras familias presionaron en las últimas décadas del siglo XVIII, para que la Casa ducal de Medinaceli les cediese una mayor participación en el gobierno local, cuyo nombramiento correspondía al duque. Después de la abolición de

106 Los datos acerca de la familia Alcalá Zamora, según WINDLER, op. cit., 1992, 102-104. Cf. MARTINISZ BARA, José Antonio, Catálogo de informaciones genealógicas de la Inquisición de Córdoba conservadas en el Archivo Histórico Nacional, tomo 1, Madrid, 1970, 24-25; Archivo Biográfico de España, Portugal e Iberoamérica, Múnich/Nueva York, 1984ss, s.v. «Alcalá Zamota», ALCAI A ZAMORA, Pedro, «Apuntes para la Historia de Priego", ed. VALVERDE MLADRID, José, Boletin de la Real Academia de Córdoba, núm. 98 (enero/junio 1978), sin paginar.

107 Cf. WINDI.ER, op. cit., 1992, sobre todo 94-107. 
la jurisdicción señorial, estas familias encontraron en la construcción de un Estado nacional mejores oportunidades de trascender los límites de su pueblo, aunque siempre apoyadas en una sólida base política local.

Una vez logrados el reconocimiento y la integración en la élite de notables de Priego, la familia Alcalá Zamora se desenvolvió hábilmente entre las redes locales y la adaptación a las nuevas circunstancias políticas e institucionales, que habrian de crear las condiciones para su posterior ascenso social. Esta forma de integración dentro del incipiente marco nacional muestra como unas clientelas entraizadas localmente instrumentalizaron los recursos estatales, y remite a las prácticas interactivas que acuñaron en especial medida la formación de Estados nacionales en la Europa mediterránea. En España, la quiebra de la monatquía del Antiguo Régimen arrastró consigo no solamente las estructuras de mediación vertebradas en torno a la jurisdicción señotial, sino también las que en el siglo XVII actuaban, con cierta eficacia, a favor de una concentración de las redes de relaciones en torno a la Corona. Las nuevas formas políticas se articulaban en una situación de extrema precariedad de recursos ${ }^{108}$, lo cual dio a las solidaridades primarias basadas en la familia, la amistad y la clientela especial importancia. Antes que al establecimiento de vínculos objetivos e impersonales, los procesos de superimposición de estructuras burocráticas condujeron más bien a la personalización de las mismas. Ésto no significa que un sector moderno, marcado por el Estado, haya tenido que componer con la inercia de unas comunidades rurales tradicionales ${ }^{109}$. La reorganización clientelar de las relaciones burocráticas no era la característica de un mundo rural arcaico, sino, por el contrario, parte de estrategias eficientes y racionales a su manera, que permitían participar de manera activa en los cambios políticos ${ }^{110}$.

Frente a una visión del Estado como una realidad externa a una sociedad «tradicional», una aproximación inspirada por el análisis de redes sugiere una interpretación distinta: un orden político plural, caracterizado por la integración de poderes concurrentes a través de la confluencia de intermediatios influyentes. Con el hundimiento de la monarquía absoluta desde finales del siglo XVIII, los notables que en los municipios disponían de poder e influencias, se

108 En este sentido, la interpretación propuesta por J. Fontana mantiene su validez, aunque se rechace el análisis en términos de clase (FONTAN $\Lambda$, Josep, La quiebra de la monarguía absousta. 1814-1820, Barcelona, ${ }^{4} 1983$ (1era. edición: 1971)).

$109 \mathrm{Cf}$, en otro contexto geográfico y social, CARDEsín DíAZ, José Maria, Tierra, trabajo y reproducción social en una aldea gallega (s. XVIII-XX): Muerte de unos, vida de otros, Madrid, 1992.

110 Insistiendo en la importancia de las transformaciones de las estructuras políticas y sociales, pero según la racionalidad propia de las redes de parentesco, amistad y clientela, la interpretación propuesta se difetencia de las aproximaciones de R. Hert, D. Ringrose y J. Cruz (HERR, Richard, «Spains, en: SPRING, David, ed., European Landed Elites in the Nineteenth Century, Baltimore, 1977 (='The Johns Hopkins Symposia in Comparative History, 8), 98-126; idem, Ru$\mathrm{ral}$ Change and Roya/ Finances in Spain at the End of the Old Regime, Berkeley/Los Angeles/Londres, 1989; RINGROSE, David R, Spain, Europe and the "Spanish Miracte", 1700-1900, Cambridge (etc.), 1996; CRUZ, op. ait., 1996).

Hipania, LVIII/2, núm. 199 (1998) 575-605 
encontraron con posibilidades añadidas de acuñar la formación de un nuevo sistema político, centralista de iure y definido como Estado, así como de hacer de la mediación de contactos un fundamento esencial de su poder.

Traducción
Alberto Cina Cosculluela 